\title{
Endothelial expression of human APP leads to cerebral amyloid angiopathy in mice
}

Yuriko Tachida ${ }^{1}$, Saori Miura ${ }^{2}$, Rie Imamaki ${ }^{3}$, Naomi Ogasawara ${ }^{3}$, Hiroyuki Takuwa ${ }^{4}$, Naruhiko Sahara ${ }^{4}$, Akihiro Shindo ${ }^{5}$, Yukio Matsuba ${ }^{6}$, Takashi Saito ${ }^{6,7}$, Naoyuki Taniguchi $^{1}$, Yasushi Kawaguchi ${ }^{3}$, Hidekazu Tomimoto ${ }^{5}$, Takaomi Saido ${ }^{6}$, and Shinobu Kitazume ${ }^{1,2, *}$

${ }^{1}$ Disease Glycomics Team, Glycobiology Research Group, Global Research Cluster, RIKEN, Saitama 351-0198, Japan ${ }^{2}$ Preparing Section for New Faculty of Medical Science, Fukushima Medical University School of Medicine, Fukushima 960-1295, Japan. ${ }^{3}$ Department of Infectious Disease Control, International Research Center for Infectious Diseases, The Institute of Medical Science, The University of Tokyo, Tokyo 108-8639, ${ }^{4}$ Department of Functional Brain Imaging Research, National Institute of Radiological Sciences, Chiba 263-8555, Japan, ${ }^{5}$ Departments of Neurology, Graduate School of Medicine, Mie University, Mie 514-8507, and ${ }^{6}$ Laboratory for Proteolytic Neuroscience, RIKEN Brain Science Institute, Saitama 351-0198, Japan,

Department of Neurocognitive Science, Institute of Brain Science, Nagoya City University Graduate School of Medical Sciences, Nagoya 467-8601, Japan

*Correspondence and requests for materials should be addressed to S.K. (email: shinobuk@fmu.ac.jp) 


\begin{abstract}
The deposition of amyloid $\beta(\mathrm{A} \beta)$ in blood vessels of the brain, known as cerebral amyloid angiopathy (CAA), is observed in more than $90 \%$ of Alzheimer's disease (AD) patients. The presence of such CAA pathology is not as evident, however, in most mouse models of AD, thereby making it difficult to examine the contribution of CAA to the pathogenesis of AD. Since blood levels of soluble amyloid precursor protein (sAPP) in rodents are less than $1 \%$ of those in humans, we hypothesized that endothelial APP expression would be markedly lower in rodents, thus providing a reason for the poorly expressed CAA pathology. Here we generated mice that specifically express human APP770 in endothelial cells. These mice exhibited an age-dependent robust deposition of $A \beta$ in brain blood vessels but not in the parenchyma. Crossing these animals with APP knock-in mice led to an expanded CAA pathology as evidenced by increased amounts of amyloid accumulated in the cortical blood vessels. These results show that both neuronal and endothelial APP contribute cooperatively to vascular A $\beta$ deposition, and suggest that this mouse model will be useful for studying disease mechanisms underlying CAA and for developing novel AD therapeutics.
\end{abstract}




\section{Introduction}

Alzheimer's disease (AD) is a progressive neurodegenerative disorder in humans and the leading cause of dementia. The pathology of $\mathrm{AD}$ is characterized by deposition of amyloid $\beta$ peptide $(\mathrm{A} \beta)$ in the brain parenchyma and blood vessels. $A \beta$ is generated by the two-step proteolytic cleavage of amyloid precursor protein (APP), $\beta$-site APP cleaving enzyme-1 (BACE1) ${ }^{1},{ }^{2}$ and $\gamma$-secretase ${ }^{3}$, the last of which is composed of four transmembrane proteins (presenilin, nicastrin, Pen2, and Aph 1$)^{4}$. When APP is alternatively cleaved at the $\alpha$-site within the A $\beta$ sequence, subsequent $\gamma$ secretase cleavage cannot produce neurotoxic $\mathrm{A} \beta$ peptide. Alternative mRNA splicing generates three major APP isoforms, APP695, APP751, and APP770, each of which exhibits cell-specific expression. In this way, neurons express APP6953, while vascular endothelial cells and platelets express APP770 ${ }^{5,6}$, and APP751 shows a relatively ubiquitous expression pattern ${ }^{7}$.

Cerebral amyloid angiopathy (CAA) is defined as the deposition of $\mathrm{A} \beta$ to the vascular walls of the meninges and brain, giving rise to intracerebral hemorrhage and cognitive impairment in the elderly ${ }^{8}$. However, epidemiological and clinicopathological data alone do not fully describe the pathological association between CAA and AD.

Impaired clearance and/or overproduction of $A \beta$ leads to its accumulation in the brains of $\mathrm{AD}$ patients ${ }^{9}$. Most neuronal $\mathrm{A} \beta$ is transported across the blood-brain barrier (BBB) into the blood $^{10}$, and as such the blood A $\beta$ can derive from a mixture of APP sources including from neurons and other tissues, all of which can contribute to vascular $\mathrm{A} \beta$ deposition. Accumulating evidence shows that several anti-A $\beta$ immunotherapies reduce the amyloid burden in brain parenchyma, while augmenting that of vascular $A \beta$ accumulation ${ }^{11,12}$, thereby indicating that $A \beta$ accumulation in the brain parenchyma and vessels is regulated in different ways. A major therapeutic concern with some anti-A $\beta$ antibodies is the possible breakdown of the blood-brain barrier (BBB) associated with brain edema and cerebral microhemorrhages, which are observed under magnetic resonance imaging as amyloid-related imaging abnormalities (ARIAs) ${ }^{13}$. To this end, the manner by which brain $A \beta$ accumulates in the vascular walls is an important issue to be clarified. Unfortunately, most $\mathrm{AD}$ model mice with parenchymal $\mathrm{A} \beta$ deposition exhibit only moderate $\mathrm{A} \beta$ deposition in the brain blood vessels ${ }^{14}$.

Based on a preliminary study showing that the level of serum sAPP in rodents is less than $1 \%$ of that compared with human serum, we explored the possibility that limited endothelial APP expression could result in a much-reduced CAA pathology in rodent models. In this study, we have developed a novel CAA mouse model that expresses human APP770 in endothelial cells. 
We show that the mice exhibit vascular $A \beta$ deposition without parenchymal $A \beta$ plaque formation accompanying breakdown of the BBB with aging.

\section{Results}

\section{Endothelial APP expression in mice.}

We first measured blood sAPP levels in rats, and found that plasma and serum sAPP levels were $70 \mathrm{pg} / \mathrm{ml}$ and $1.1 \mathrm{ng} / \mathrm{ml}$, respectively (Fig. 1a). These levels are markedly lower (0.3 \%) than those measured in human samples, in which plasma and serum sAPP770 levels were 47 and $410 \mathrm{ng} / \mathrm{ml}$, respectively. Serum sAPP770 levels are substantially higher than plasma sAPP770 levels because platelets store sAPP770 in $\alpha$-granules and release it into the serum upon activation ${ }^{6,15}$. In mice, blood sAPP levels were even undetectable in some cases. Even though APP is considered to be expressed ubiquitously ${ }^{16}$, we hypothesized that endothelial APP expression might be limited in rodents, and that this scenario could result in markedly lower levels of blood sAPP and poor CAA pathology in most $\mathrm{AD}$ mouse models. To test this hypothesis, we developed a new mouse model that specifically expresses human APP770 with the Swedish (KM670/671NL) mutation ${ }^{17}$ in vascular endothelial cells. We first generated floxed hAPP770 ${ }_{\mathrm{NL}}$ mice (EC-APP770-) under the CMV early enhancer/chicken $\beta$ actin promoter (Fig. 1b, c) and then crossed these mice with Tie2Cre mice, which express Cre recombinase in the endothelial cells by Tie 2 promoter $^{18}$, to obtain double Tg mice (EC-APP770 ${ }^{+}$). Immunohistochemical analyses of brain sections from these mice showed that the human APP770 signal is found in endothelial marker PECAM positive-cells in EC-APP $770^{+}$mice but not in EC-APP770- mice (Fig. 1d). We next used brains from EC-APP770 and EC-APP770 mice to isolate endothelial cells, these being positive for PECAM and negative for the neuronal marker $\beta$ III-tubulin (Fig. 1e). Western blot analysis showed that an hAPP770 signal was not detectable in brain lysates from either type of mouse. In contrast, we could detect an hAPP770 signal in the lysates of brain endothelial cells isolated from EC-APP770 ${ }^{+}$mice but not from EC-APP770 ${ }^{-}$mice. Taken together, these data indicate that hAPP770 is specifically expressed in the endothelial cells of EC-APP $770^{+}$mice. Using an anti-APP antibody that detects the carboxy-terminal region of APP that is common to both mouse and human APP, we estimated the expression level of endothelial hAPP770 in EC-APP770 ${ }^{+}$mice to be about three times higher than that in EC-APP770- mice.

\section{Aged EC-APP770 ${ }^{+}$mice show A $\beta$ deposition in brain blood vessels.}


Since a considerable amount of the extracellular region of endothelial APP770 is cleaved for secretion $^{5}$, human sAPP770 should be detectable in the serum of EC-APP770 $0^{+}$mice. Indeed, serum sAPP770 levels in these mice were $\sim 7.6 \mu \mathrm{g} / \mathrm{ml}$ whereas they were undetectable in ECAPP770 mice (Fig. 2a). We also measured sAPP770 $\beta$ levels in EC-APP $770^{+}$mice to be $\sim 90$ $\mathrm{ng} / \mathrm{ml}$, which is less than $2 \%$ of total sAPP770. This compares favorably with the case of human plasma, in which the sAPP $\alpha$ level is about 15 -fold that of the sAPP $\beta$ leve $1^{19}$. Cultured endothelial cells secrete both $A \beta 40$ and $A \beta 42$ in the culture medium ${ }^{5}$. In EC-APP $770^{+}$mice, serum $A \beta 40$ was detectable whereas the A $\beta 42$ level was below the detection limit for our analysis. To our knowledge, these data clearly show for the first time that endothelial APP contributes to blood A $\beta$ levels. Two-year-old EC-APP770 ${ }^{+}$mice showed somewhat reduced serum A $\beta 40$ levels as compared with 1-year-old mice.

We next sought to determine whether EC-APP $770^{+}$mice show increased CAA pathology with aging. Immunohistochemical analyses showed that EC-APP770+ mice exhibit A $\beta$ deposition in the walls of leptomeningeal and cortical arteries at 12 months of age but not at 6 months (Fig. 2b). In contrast, such amyloidosis was absent in EC-APP770- mice even at 12 months. We also employed 82E1 antibody to preferentially detect the $\mathrm{A} \beta$ peptides but not full length APP; in this way, 82E1-positive signals were found in the cerebral vessels of EC-APP770 ${ }^{+}$ mice but not of EC-APP770- mice at 15 months of age (Fig. 2c). Granular 82E1-positive signals observed in both types of aged mice are considered to be derived from lipofuscin. Furthermore, tail vein injection of $82 \mathrm{E} 1$ antibody ${ }^{20}$ resulted in longer retention of the antibody in the cerebral blood vessels of 22-month-old EC-APP770 ${ }^{+}$mice, compared to EC-APP770- mice (Supplementary Fig. 1). To verify the presence of amyloid plaque deposition in EC-APP770 mice, we used 1-fluoro-2,5-bis(3-carboxy-4-hydroxystyryl)benzene (FSB), which preferentially binds amyloid plaque ${ }^{21}$. In brain sections from 15-month-old EC-APP770 ${ }^{+}$mice, FSB signals were co-localized with the signal for phalloidin-Alexa546, a vascular smooth muscle cell marker (Fig. 2d) ${ }^{22}$. Magnified radial images of blood vessels showed that FSB signals were present in the luminal regions of phalloidin-Alexa546-positive vessels. These observations show that endothelial APP770 expression in mice leads to cerebrovascular A $\beta$ deposits in an age-dependent manner, as we had hypothesized, and that EC-APP $770^{+}$mice could serve as useful models for studying CAA pathology.

\section{Deposition of activated complement components in brain blood vessels along with BBB leakage are prominent features in aged $\mathrm{EC}-\mathrm{APP} 770^{+}$mice.}


Since the complement system represents a key role for neuroinflammation, and given that complement proteins are associated with cerebral microvascular $A \beta$ deposition ${ }^{23} 24,25$, we next investigated whether activated complement proteins are localized to cortical blood vessels. In 15month-old EC-APP770 ${ }^{+}$mice, relatively strong C3b signals were co-localized with PECAMpositive cortical blood vessels (Fig. 3a). C3b binding can activate the membrane attack component (MAC) involving C5b-9. Indeed, C5b-9 signals were significantly higher in the cortical blood vessels of 15-month-old EC-APP770 ${ }^{+}$mice (Fig. 3a ,b). C5 convertase containing $\mathrm{C} 3 \mathrm{~b}$ generates $\mathrm{C} 5 \mathrm{a}$ anaphylatoxin. We found that serum $\mathrm{C} 5 \mathrm{a}$ levels in EC-APP770 ${ }^{+}$mice were significantly higher than those in EC-APP770- mice (Fig. 3c). Since a BBB leakage is closely associated with $\mathrm{CAA}^{26}$, we next characterized the integrity of the BBB by measuring leakage of fibrin, an endogenous plasma protein ${ }^{10}$. Perivascular fibrin leakage was observed in a limited number of 12-month-old EC-APP770 ${ }^{+}$mice, whereas none of the aged EC-APP770 mice analyzed showed such fibrin leakage (Fig. 3d). To assess the BBB breakdown in a more quantitative manner, we employed an in vivo assay to test blood vessel permeability in brains ${ }^{27}$. Following the intraperitoneal injection of Evans blue, a BBB-impermeant dye that binds to albumin, significant levels of Evans blue were detected in around half of the 15-month-old ECAPP $770^{+}$mouse brains analyzed (Fig. 3e), but were absent in the brains of similarly aged ECAPP770- mice.

\section{EC-APP770 ${ }^{+}$mice crossed with APP-KI mice exhibited marked A $\beta$ deposition in blood vessels.}

We next considered how endothelial APP expression influences AD pathology. We crossed ECAPP $770^{+}$mice with standard $A p p^{\mathrm{NL}-\mathrm{F} / \mathrm{NL}-\mathrm{F}} \mathrm{AD}$ model mice and evaluated amyloid plaque formation in FSB-stained brain sections from 15 -month-old EC-APP770 ${ }^{+}$, EC-APP $770^{+}:$App $^{\mathrm{NL}-}$ F/NL-F, EC-APP770: $A p p^{\text {NL-F/NL-F }}$, and $A p p^{\text {NL-F/NL-F }}$ mice. In low-magnification images, signals of vascular amyloid deposition were relatively weak in EC-APP770 ${ }^{+}$mice (Fig. 4a). In contrast, $A p p^{\text {NL-F/NL-F }}$ mice exhibited weak vascular amyloid deposition in addition to parenchymal amyloid plaque.

The number of parenchymal plaques in cortical regions of EC-APP770 ${ }^{+}: A p p^{\text {NL-F/NL-F }}$ mice was about two times higher than that in $A p p^{\text {NL-F/NL-F }}$ mice (Supplementary Fig. 2). However, as a similar increase was also observed in EC-APP770- $\mathrm{App}^{\mathrm{NL}-\mathrm{F} / \mathrm{NL}-\mathrm{F}}$ mice, we speculated that this could be due to an undesired effect arising from insertion of the floxed hAPP770 transgene. We then decided to determine the integration site of the transgene by next-generation sequencing, and 
found that it was within the intron between exons 3 and 4 of the $I k z f 3$ gene in chromosome 11 (Supplementary Fig. 3a). The integration site was confirmed by genomic PCR using primers against genomic DNA and the transgene, respectively (Supplementary Fig. $3 b$ ). The $I k z f 3$ gene encodes Aiolos, a member of the Ikaros family of zinc-finger proteins, which shows restricted expression in the lymphoid system, and regulates lymphocyte differentiation ${ }^{28}$. We measured Aiolos expression levels in the spleens of EC-APP770 and wild type mice and found that expression in EC-APP770 mice was 1.4 times higher than that of wild type mice (Supplementary Fig. 3c and d), which could result in a phenotypic alteration in these animals after crossing with AD model mice.

A most striking feature observed in EC-APP $770^{+}: A p p^{\mathrm{NL}-\mathrm{F} / \mathrm{NL}-\mathrm{F}}$ mice was the massive amyloid plaque deposition in cortical blood vessels (Fig. 4b). The percentage of FSB-positive area in the cortex was highest in EC-APP770 $: A p p^{\text {NL-F/NL-F }}$ mice (Fig. 4c). In order to characterize amyloid plaque characteristics in greater detail, we performed integrated morphometry analysis in which FSB-positive amyloid plaques were counted and classified on the basis of size. Amyloid deposition to larger vessels, corresponding to plaque sizes over $400 \mu \mathrm{m}^{2}$, was prominent in EC$\mathrm{APP} 770^{+}: \mathrm{App}^{\mathrm{NL}-\mathrm{F} / \mathrm{NL}-\mathrm{F}}$ mice (Fig. 4d). As biochemical analyses previously showed that A $\beta$ isoforms shorter than 42 residues form a component of the cerebrovascular amyloid from AD patients $^{29}$, we next performed immunohistochemical analyses on brain sections from EC$\mathrm{APP} 770^{+}: \mathrm{App}^{\mathrm{NL}-\mathrm{F} / \mathrm{NL}-\mathrm{F}}$ mice to detect different A $\beta$ species. An A $\beta 40$ signal was co-localized with that of PECAM, and thus restricted to brain blood vessels, while an A $\beta 42$ signal was observed exclusively in the brain parenchyma (Fig. 4e, f). Anaysis of EC-APP770 $:$ App $^{\text {NL-F/NL-F }}$, ECAPP770: $A p p^{\mathrm{NL}-\mathrm{F} / \mathrm{NL}-\mathrm{F}}$, and $A p p^{\mathrm{NL}-\mathrm{F} / \mathrm{NL}-\mathrm{F}}$ mice shows that significantly higher levels of A $\beta 40$ were accumulated in EC-APP $770^{+}: A p p^{\mathrm{NL}-\mathrm{F} N \mathrm{NL}-\mathrm{F}}$ mice, as compared with $A p p^{\mathrm{NL}-\mathrm{F} \text { NL-F }}$ mice, while accumulation of $A \beta 42$ is not different in these mice (Supplementary Fig. 4, Fig. 4g).

Taken together, our newly developed mouse model could serve as a useful research tool to study the disease mechanism underlying CAA pathology.

\section{Discussion}

It remains unclear whether the $A \beta$ in accumulated plaque in the cortical blood vessels is derived from the circulation, the blood vessel wall itself, or from the central nervous system ${ }^{30}$. High levels of plasma $\mathrm{A} \beta$ do not cause $\mathrm{CAA}$ in transgenic mice expressing signal peptide plus the carboxylterminal region of APP that contains $A \beta^{31}$. Nevertheless, as intraperitoneal inoculation with $A \beta$ - 
rich brain extracts (possibly containing $\mathrm{A} \beta$ oligomers) from $\mathrm{AD}$ model mice can induce $\mathrm{CAA}$ in APP-overexpressing mice ${ }^{32}$, circulating $A \beta$ oligomers may play a seeding or transmission function in vascular $A \beta$ deposition. Neuronal APP-expressing mice also exhibit mild CAA pathology, supporting the notion that neuronal $A \beta$ could be a source of CAA. In this study, we show for the first time that endothelial expression of human APP contributes to vascular A $\beta$ deposition in mice. Remarkably, by crossing with hAPP knock-in mice, in which neuronal APP is expressed, the CAA pathology is markedly exacerbated, also supporting the idea that impaired perivascular drainage of $A \beta$ in the interstitial fluid (ISF) could contribute to CAA pathology ${ }^{33,34}$. These results indicate that both endothelial APP and neuronal APP co-operatively contribute to the progression of CAA pathology. Several kinds of anti-A $\beta$ antibodies have been developed as $\mathrm{AD}$ immunotherapeutics and are currently in the clinical trials ${ }^{35}$. However, administration of anti$A \beta$ antibodies often causes amyloid- related imaging abnormalities (ARIA), suggestive signals for vasogenic oedema and sulcal effusions (ARIA-E) and microhemorrhage and haemosiderin deposits (ARIA-H), as adverse effects. Since the aged EC-APP770 ${ }^{+}$mice characteristically exhibit vascular abnormalities, such as vascular deposition of activated complement components and enhanced BBB leakage, the mice would be useful to study the degree of ARIA induced by administration of anti- $\mathrm{A} \beta$ antibodies and basic molecular mechanism of ARIA.

A disadvantage associated with using EC-APP $770^{+}$mice is the increased expression of Aiolos due to insertion of the floxed APP transgene within the intron of the gene encoding for Aiolos, Ikzf3. Aiolos overexpression has been reported in B cells from patients with systemic lupus erythematosus $(\mathrm{SLE})^{36}$, while it was recently shown that the cerebral small blood vessel disease burden is increased in SLE ${ }^{37}$. By crossing with AD model mice, both EC-APP770 ${ }^{+}$and EC-APP770 mice exhibited amyloid plaques in the cerebral small blood vessels, an effect that is likely related to the SLE-like features. Further to this, the endothelial-specific angiopoietin 2Tie2 ligand-receptor system has been identified as a major regulator of endothelial inflammation in SLE. Mating female EC-APP770 mice with wild type male mice should be avoided, since this results in offspring with APP770 expression throughout the body, possibly due to aberrant Tie2 activation in the pregnant mice ${ }^{38}$.

Even though $A \beta 42$ has a higher propensity than $A \beta 40$ to aggregate, immunohistochemical analyses of EC-APP $770^{+}: A p p^{\mathrm{NL}-\mathrm{F} / \mathrm{NL}-\mathrm{F}}$ mice showed that vascular amyloid consists mostly of A $\beta 40$, as has been reported in the case of $\mathrm{AD}$ patients ${ }^{29}$, while parenchymal amyloid consists mostly of A $\beta 42$. One interesting possibility is that endothelial cells in the aged mice could induce specific molecule(s) with high affinity for the A $\beta 40$ oligomer. Brain sections from aged EC-APP $770^{+}$ 
mice stained with FSB and Alexa546-phalloidin to detect amyloid and vascular smooth muscle cells, respectively, showed that amyloid plaques are mainly located in the luminal side of vascular endothelium. However, longitudinal images of vessel sections showed a vascular FSB signal outside of the smooth muscle cells, possibly due to the disruption of vascular smooth muscle cells, as has been reported in APP overexpressing mice ${ }^{39}$. Indeed, breakdown of the BBB is clearly evident in aged EC-APP $770^{+}$mice .

Taken together, our newly developed EC-APP $770^{+}$mice could serve as a useful research tool to study the disease mechanism underlying CAA pathology and the mechanistic interactions between $\mathrm{CAA}$ and $\mathrm{AD}$.

\section{Methods}

\section{Materials}

Sources of materials used in this study were as follows: tissue culture medium and reagents, including Dulbecco's modified Eagle's medium (DMEM), were from Invitrogen; all other chemicals were from Sigma or Wako Chemicals. Anti-hAPP monoclonal antibody (rat, 1D1) ${ }^{40}$ was conjugated with Alexa 555 using a HyLyte Fluor ${ }^{\mathrm{TM}} 555$ Labeling $\mathrm{Kit}^{-\mathrm{NH}_{2}}$ (Dojindo). Other commercially available antibodies used were anti-APP (mouse, 22C11, Chemicon), anti-sAPP $\alpha$ (mouse, 6E10, BioLegend), anti-human APP770 (rabbit, Japan-IBL), anti-EEA1 and anti-adaptin $\gamma$ (mouse, BD Transduction Laboratories), Alexa Fluor 488-anti-A $\beta$ (6E10, BioLegend), antiPECAM (rat, MEC13.3, BioLegend), anti-tubulin $\beta 3$ (mouse, TUJ1, BioLegend), anti-CD146 (rat, ME-9F1, BioLegend), anti-GAPDH (mouse, MAB374, Chemicon), anti-FLAG (M2) (mouse, Sigma), and anti-APP (APP(C)), anti-APP OX2, and anti-human sAPP $\beta$ (rabbit, IBL-Japan). pCALNL5 (RDB01862, RIKEN BioResource Center) plasmid was from Dr. I. Saito (University of Tokyo).

\section{Animal Use and Care.}

All animal experiments were performed at RIKEN, Fukushima Medical University, or the National Institute of Radiological Sciences in compliance with their respective guidelines for animal experiments.

\section{Generation of EC-APP770 ${ }^{+}$mice}

Endothelial APP770-overexpressing mice $\left(\mathrm{EC}-\mathrm{APP} 770^{+}\right)$were generated with the help of the 
Support Unit for Animal Resources Development in RIKEN BSI. The plasmid pCANLN5hAPP770 was generated by inserting the human APP770 Swedish mutant (hAPP770 $0_{\mathrm{NL}}$ ) into the pCALNL5 vector ${ }^{41}$. The resulting plasmid has the neomycin-resistant (neoR) gene flanked by two loxP sites under the CMV early enhancer/chicken $\beta$ actin promoter (CAGp), followed by the hAPP770Sw sequence. pCANLN5-hAPP770 was linearized and injected into C57BL/6J blastocysts. We extracted DNA from ear punches of mouse pups and identified nine F1 generation mice by PCR using the following cocktail of primers ${ }^{42}$ : 5'-ATCTCGGAAGTGAAGATG-3', 5'ATCTCGGAAGTGAATCTA-3', 5'-TGTAGATGAGAACTTAAC-3' and 5'CGTATAATGTATGCTATACGAAG-3'. Heterozygous EC-APP770 ${ }^{-}$mice were then crossed with Tie2-Cre mice ${ }^{18}$. The $A P P 770_{N L}$ allele was identified by PCR (forward, 5'AGCCGCAGCCATTGCCTTTTATGGTA-3', reverse, 5'CAGGTCGGTCTTGACAAAAAGAACCG-3' for $A P P 770_{N L}$ ). The Tie2-Cre allele was identified by PCR (forward, 5'-ACATGTTCAGGGATCGCCAG-3', reverse, 5'TAACCAGTGAAACAGCATTGC-3'). To obtain EC-APP770 ${ }^{+}$and EC-APP770- mice, male EC-APP $770^{+}$mice were mated with wild type C57BL/6 female mice. EC-APP770 ${ }^{+}$mice were crossed with AD model $\left(A p p^{\mathrm{NL}-\mathrm{F} / \mathrm{NL}-\mathrm{F}}\right)$ mice $^{42}$.

\section{Determination of the integration site of the APP transgene.}

The location of the hAPP770 transgene insertion was determined using Illumina NGS (Hokkaido System Science CO., Ltd). The source code to perform the integration site analysis ${ }^{43}$ is available at https://github.com/hbc/li_hiv. Genomic PCR analyses were performed to confirm the insertion loci using F2 (5'- $\quad$ CTTCTGTTGTTTGGCTTTAT-3'), GACGTCAATGGAAAGTCCCT-3'), R2 (5'-GTtGGTCTCATGAGGCAAGT-3'), 2B (5'GACGTCAATGGAAAGTCCCT-3') and R3 (5'-TGTGTGTGGCAAACACTTTG-3') primers.

\section{Immunohistochemical and histochemical studies}

To prepare brain sections, mice were anesthetized with medetomidine-midazolam-butorphanol and then transcardially perfused with PBS first and with $0.1 \mathrm{M}$ phosphate-buffered 4\% paraformaldehyde. Brains were removed and sequentially immersed in the same fixative for $16 \mathrm{~h}$ and then phosphate-buffered $30 \%$ sucrose for $16 \mathrm{~h}$ at $4^{\circ} \mathrm{C}$. Sagittal or coronal (30- $\mu \mathrm{m}$ thickness) sections were immunostained using the floating method. Briefly, sections were permeabilized with $0.3 \%$ Triton X-100 in 1\% BSA -PBS for 30 min first and with $5 \%$ goat serum-PBS for 60 $\min$. The sections were then incubated with primary and secondary antibodies and DAPI. Detailed 
descriptions of the primary and secondary antibodies used are provided in Supplementary Table 1. For the detection of amyloidosis, 1-fluoro-2,5-bis(3-carboxy-4-hydroxystyryl)benzene (FSB) was used ${ }^{21}$. Stained sections were observed using an Olympus FV-1000 confocal microscope. We quantified immunoreactive areas using MetaMorph imaging software (Universal Imaging Corp., West Chester, USA) as previously described ${ }^{42}$. To reduce the variance among tissue sections, data were averaged from at least four sections per mouse.

\section{In Vivo Fluorescence Imaging}

Anti-amyloid $\beta(A \beta)$ oligomer antibody (82E1, IBL) was labeled with Alexa Fluor 555 (Life Technologies) according to the manufacturer's protocol. Briefly, $100 \mu 1$ of antibody $(1 \mathrm{mg} / \mathrm{ml})$ coupled with Alexa Fluor dye was mixed and incubated in a $100 \mathrm{mM}$ sodium bicarbonate solution for one hour at $25^{\circ} \mathrm{C}$. The labeled $82 \mathrm{E} 1$ antibody was separated though a purification column. The purified antibody was kept in darkened vials maintained at $4^{\circ} \mathrm{C}$ before use.

EC-APP $770^{+}$and EC-APP770 mice (22 months old) were used in this experiment. A chronic cranial window was surgically attached to the bone of the skull as previously described ${ }^{44}$. In vivo fluorescence imaging was conducted by two-photon microscopy (TCS-SP5 MP, Leica Microsystems $\mathrm{GmbH}$, Wetzlar, Germany) with an excitation wavelength of $900 \mathrm{~nm}$. The emission signal was separated by a beam splitter $(560 / 10 \mathrm{~nm})$ and detected with a band-pass filter for labeled 82E1 (610/75 nm). A single image plane consisted of 1024 x 1024 pixels, while the inplane pixel size was $0.25-0.45 \mu \mathrm{m}$ depending on the instrument zoom factor used. Two-photon imaging was performed prior to and at 1 minute, 1 day and 2 days after the intravenous injection of labeled 82E1 antibody. Volume images were acquired with a z-step size of $2.5 \mu \mathrm{m}$ up to a maximum depth of $0.2 \mathrm{~mm}$ from the cortical surface.

\section{Isolation of endothelial cells}

Endothelial cells were isolated from mouse brains as previously reported ${ }^{5,45}$, except for the use of anti-CD146 antibody (BioLegend, clone:ME-9F1) coupled with Dynabeads Sheep anti-Rat IgG (Thermo Fisher Scientific).

\section{Western blot experiments}

Cells from mouse brain or spleen tissues were lysed with T-PER Tissue Protein Extraction Reagent (Thermo) containing Complete Protease Inhibitor Cocktail (Roche Applied Science). Protein concentrations were determined with BCA protein assay reagents (Pierce). Samples (25 
- $40 \mu \mathrm{g}$ of protein) were subjected to SDS-PAGE (5-20\% gradient gel) and transferred to nitrocellulose membranes. For western blot analyses, following incubation with 5\% non-fat dried milk in TBS-containing $0.1 \%$ Tween-20, the membranes were incubated with primary antibodies and horseradish peroxidase (HRP)-labeled secondary antibodies. Signals were detected with SuperSignal West Dura Extended Duration Substrate (Thermo Fisher Scientific) using an ImageQuant LAS-4000 Mini imager (GE Healthcare). Intensities of the resultant protein bands were quantified using ImageQuant TL software (GE Healthcare).

\section{Quantification of sAPP, $A \beta$}

To measure sAPP770, sAPP770 $\beta, A \beta 40$ and A $\beta 42$ in plasma or serum, a Human sAPP Total Assay Kit, an sAPP $\beta-w$ Assay Kit (highly sensitive) (IBL-Japan), a Human / Rat ßamyloid (40) ELISA kit and a Human / Rat ßamyloid (42) assay kit High-Sensitive (Wako) were used, respectively. To measure rat sAPP, a Mouse / Rat sAPP $\alpha$ (highly sensitive) Assay Kit (IBLJapan) was used. A mouse complement component C5a DuoSet ELISA (DY2150, R\&D systems) was used to measure serum $\mathrm{C} 5 \mathrm{a}$ in mice.

\section{Evans blue assay.}

To assess BBB integrity, mice were administered $0.2 \mathrm{ml}$ of $2 \%$ Evans blue (Sigma) by intraperitoneal injection ${ }^{46}$. Six hours later, the mice were anesthetized with medetomidinemidazolam-butorphanol and perfused with PBS. Brain and lung tissue (100 mg each) homogenates were incubated with $1 \mathrm{ml}$ formamide (Sigma) at $55^{\circ} \mathrm{C}$ for $24 \mathrm{~h}$ to extract the Evans blue. The formamide / Evans blue mixture was centrifuged, and the supernatant absorbance was measured at $610 \mathrm{~nm}$ with a microplate reader.

\section{Statistical analysis}

All data are shown as mean \pm SEM. For comparison between two groups, statistical analyses were performed by Student's $t$-test. Multiple comparison tests were performed using GraphPad Prism 7 software. Normality was tested using a D'Agostino-Pearson normality test. For comparisons among three or more groups, one-way analysis of variance (ANOVA) followed by a post-hoc test (Tukey's multiple comparison test) or Bonferroni's multiple comparison test were performed. The data were collected and processed in a randomized and blinded manner.

\section{Data availability}


All relevant data are available from the corresponding authors upon reasonable request. The source data underlying Figs. 1a, 1c, 1e, 2a, 3a, 3d, 4b, 4c, 4g-i, 5b, 5c, and Supplementary figure 2 are provided in the Source data file. Antibodies used for western blot (WB) and immunohistochemical (IHC) analyses are shown in Supplementary Table 1.

\section{Acknowledgment}

We thank M. Yanagisawa (University of Texas Southwestern Medical Center) for providing Tie2Cre transgenic mice, I. Saito (The Institute of Medical Science, The University of Tokyo) for the pCALNL5 vector, S. Lichtenthaler (DZNE) for anti-hAPP(1D1) antibody, and staff at the BSI Research Resource Center for producing APP770 (flox) mice. This work was supported by AMED (grant number JP18am0101036) to SK, the Mitsubishi Foundation (to SK), and KAKENHI (16K08601 to SK and 25840043 to YT).

\section{Author contributions}

Y.T., S.M., R.I., N.O., H.T., A.S. and Y.M. designed and performed the experiments. S.K. conceived the study, designed the experiments and wrote the manuscript. H.T., T. Saito., Y.K., N.S., N.T., and T. Saido designed the experiments and contributed to data interpretation.

\section{Competing financial interests}

The authors declare no competing financial interests.

\section{References}

1. Yan R, Vassar R. Targeting the $\beta$ secretase BACE1 for Alzheimer's disease therapy. The Lancet Neurology 13, 319-329 (2014).

2. Vassar R, Kovacs DM, Yan R, Wong PC. The beta-secretase enzyme BACE in health and Alzheimer's disease: regulation, cell biology, function, and therapeutic potential. $J$ Neurosci 29, 12787-12794 (2009).

3. Wertkin AM, et al. Human neurons derived from a teratocarcinoma cell line express solely the 695 -amino acid amyloid precursor protein and produce intracellular betaamyloid or A4 peptides. Proc Natl Acad Sci U S A 90, 9513-9517 (1993).

4. De Strooper B, Vassar R, Golde T. The secretases: enzymes with therapeutic potential in Alzheimer disease. Nat Rev Neurol 6, 99-107 (2010). 
5. Kitazume S, et al. Brain endothelial cells produce amyloid \{beta\} from amyloid precursor protein 770 and preferentially secrete the O-glycosylated form. J Biol Chem 285, 40097-40103 (2010).

6. Kitazume S, et al. Soluble amyloid precursor protein 770 is released from inflamed endothelial cells and activated platelets: a novel biomarker for acute coronary syndrome. J Biol Chem 287, 40817-40825 (2012).

7. Ponte $\mathrm{P}$, et al. A new A4 amyloid mRNA contains a domain homologous to serine proteinase inhibitors. Nature 331, 525-527 (1988).

8. Charidimou A, Gang Q, Werring DJ. Sporadic cerebral amyloid angiopathy revisited: recent insights into pathophysiology and clinical spectrum. J Neurol Neurosurg Psychiatry 83, 124-137 (2012).

9. Mawuenyega KG, et al. Decreased clearance of CNS beta-amyloid in Alzheimer's disease. Science 330, 1774 (2010).

10. Tarasoff-Conway JM, et al. Clearance systems in the brain-implications for Alzheimer disease. Nat Rev Neurol 11, 457-470 (2015).

11. Nicoll JA, Wilkinson D, Holmes C, Steart P, Markham H, Weller RO. Neuropathology of human Alzheimer disease after immunization with amyloid-beta peptide: a case report. Nat Med 9, 448-452 (2003).

12. Pfeifer M, et al. Cerebral hemorrhage after passive anti-Abeta immunotherapy. Science 298, 1379 (2002).

13. Sperling R, et al. Amyloid-related imaging abnormalities in patients with Alzheimer's disease treated with bapineuzumab: a retrospective analysis. The Lancet Neurology 11, 241-249 (2012).

14. Herzig MC, et al. Abeta is targeted to the vasculature in a mouse model of hereditary cerebral hemorrhage with amyloidosis. Nat Neurosci 7, 954-960 (2004).

15. Bush AI, et al. The amyloid precursor protein of Alzheimer's disease is released by human platelets. J Biol Chem 265, 15977-15983 (1990).

16. Muller UC, Zheng H. Physiological functions of APP family proteins. Cold Spring Harb Perspect Med 2, a006288 (2012).

17. Citron M, et al. Mutation of the beta-amyloid precursor protein in familial Alzheimer's disease increases beta-protein production. Nature 360, 672-674 (1992).

18. Kisanuki YY, Hammer RE, Miyazaki J, Williams SC, Richardson JA, Yanagisawa M. Tie2-Cre transgenic mice: a new model for endothelial cell-lineage analysis in vivo. 
Dev Biol 230, 230-242 (2001).

19. Ray B, Long JM, Sokol DK, Lahiri DK. Increased secreted amyloid precursor proteinalpha (sAPPalpha) in severe autism: proposal of a specific, anabolic pathway and putative biomarker. PLoS One 6, e20405 (2011).

20. Horikoshi Y, Mori T, Maeda M, Kinoshita N, Sato K, Yamaguchi H. Abeta N-terminalend specific antibody reduced beta-amyloid in Alzheimer-model mice. Biochem Biophys Res Commun 325, 384-387 (2004).

21. Higuchi M, Iwata N, Matsuba Y, Sato K, Sasamoto K, Saido TC. 19F and 1H MRI detection of amyloid beta plaques in vivo. Nat Neurosci 8, 527-533 (2005).

22. Han BH, et al. Resorufin analogs preferentially bind cerebrovascular amyloid: potential use as imaging ligands for cerebral amyloid angiopathy. Mol Neurodegener 6, 86 (2011).

23. Rogers J, et al. Complement activation by beta-amyloid in Alzheimer disease. Proc Natl Acad Sci U S A 89, 10016-10020 (1992).

24. Verbeek MM, Otte-Holler I, Veerhuis R, Ruiter DJ, De Waal RM. Distribution of A beta-associated proteins in cerebrovascular amyloid of Alzheimer's disease. Acta Neuropathol 96, 628-636 (1998).

25. Matsuo K, et al. Complement Activation in Capillary Cerebral Amyloid Angiopathy. Dement Geriatr Cogn Disord 44, 343-353 (2017).

26. Hardy J, Allsop D. Amyloid deposition as the central event in the aetiology of Alzheimer's disease. Trends Pharmacol Sci 12, 383-388 (1991).

27. Radu M, Chernoff J. An in vivo assay to test blood vessel permeability. J Vis Exp, e50062 (2013).

28. Morgan B, et al. Aiolos, a lymphoid restricted transcription factor that interacts with Ikaros to regulate lymphocyte differentiation. EMBO J 16, 2004-2013 (1997).

29. Prelli F, Castano E, Glenner GG, Frangione B. Differences between vascular and plaque core amyloid in Alzheimer's disease. J Neurochem 51, 648-651 (1988).

30. Auriel E, Greenberg SM. The pathophysiology and clinical presentation of cerebral amyloid angiopathy. Curr Atheroscler Rep 14, 343-350 (2012).

31. Fukuchi K, et al. High levels of circulating beta-amyloid peptide do not cause cerebral beta-amyloidosis in transgenic mice. Am J Pathol 149, 219-227 (1996).

32. Eisele YS, et al. Peripherally applied Abeta-containing inoculates induce cerebral betaamyloidosis. Science 330, 980-982 (2010). 
33. Weller RO, Massey A, Newman TA, Hutchings M, Kuo YM, Roher AE. Cerebral amyloid angiopathy: amyloid beta accumulates in putative interstitial fluid drainage pathways in Alzheimer's disease. Am J Pathol 153, 725-733 (1998).

34. Hawkes CA, et al. Perivascular drainage of solutes is impaired in the ageing mouse brain and in the presence of cerebral amyloid angiopathy. Acta Neuropathol 121, 431443 (2011).

35. Gallardo G, Holtzman DM. Antibody Therapeutics Targeting Abeta and Tau. Cold Spring Harb Perspect Med 7, (2017).

36. Nakayama Y, Kosek J, Capone L, Hur EM, Schafer PH, Ringheim GE. Aiolos Overexpression in Systemic Lupus Erythematosus B Cell Subtypes and BAFF-Induced Memory B Cell Differentiation Are Reduced by CC-220 Modulation of Cereblon Activity. J Immunol 199, 2388-2407 (2017).

37. Wiseman SJ, et al. Cerebral Small Vessel Disease Burden Is Increased in Systemic Lupus Erythematosus. Stroke 47, 2722-2728 (2016).

38. Kumpers $\mathrm{P}$, et al. The Tie2 receptor antagonist angiopoietin 2 facilitates vascular inflammation in systemic lupus erythematosus. Ann Rheum Dis 68, 1638-1643 (2009).

39. Christie R, Yamada M, Moskowitz M, Hyman B. Structural and functional disruption of vascular smooth muscle cells in a transgenic mouse model of amyloid angiopathy. Am J Pathol 158, 1065-1071 (2001).

40. Hofling C, et al. Differential transgene expression patterns in Alzheimer mouse models revealed by novel human amyloid precursor protein-specific antibodies. Aging Cell 15, 953-963 (2016).

41. Kanegae $\mathrm{Y}$, et al. Efficient gene activation in mammalian cells by using recombinant adenovirus expressing site-specific Cre recombinase. Nucleic Acids Res 23, 3816-3821 (1995).

42. Saito T, et al. Single App knock-in mouse models of Alzheimer's disease. Nat Neurosci 17, 661-663 (2014).

43. Sunshine S, et al. HIV Integration Site Analysis of Cellular Models of HIV Latency with a Probe-Enriched Next-Generation Sequencing Assay. J Virol 90, 4511-4519 (2016).

44. Tomita $\mathrm{Y}$, et al. Long-term in vivo investigation of mouse cerebral microcirculation by fluorescence confocal microscopy in the area of focal ischemia. J Cereb Blood Flow Metab 25, 858-867 (2005). 
45. Buxbaum JD, et al. Evidence that tumor necrosis factor alpha converting enzyme is involved in regulated alpha-secretase cleavage of the Alzheimer amyloid protein precursor. J Biol Chem 273, 27765-27767 (1998).

46. Huang Y, et al. Repopulated microglia are solely derived from the proliferation of residual microglia after acute depletion. Nat Neurosci 21, 530-540 (2018). 


\section{Fig 1}

a

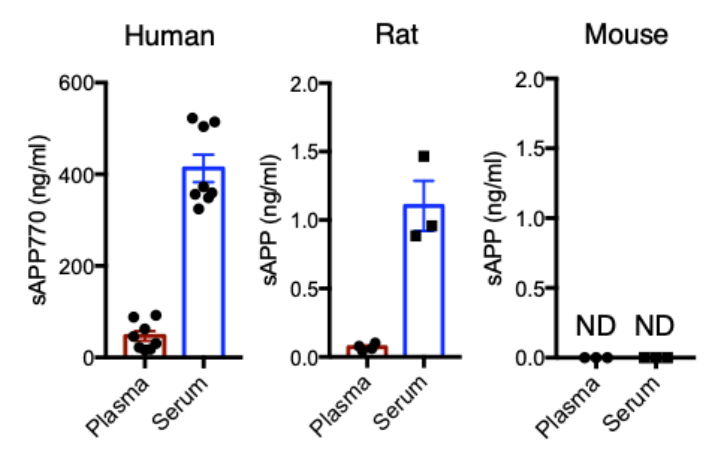

C

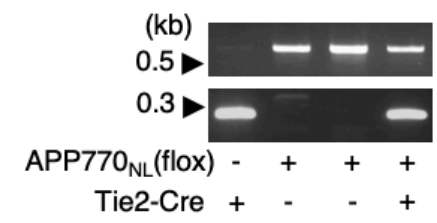

d

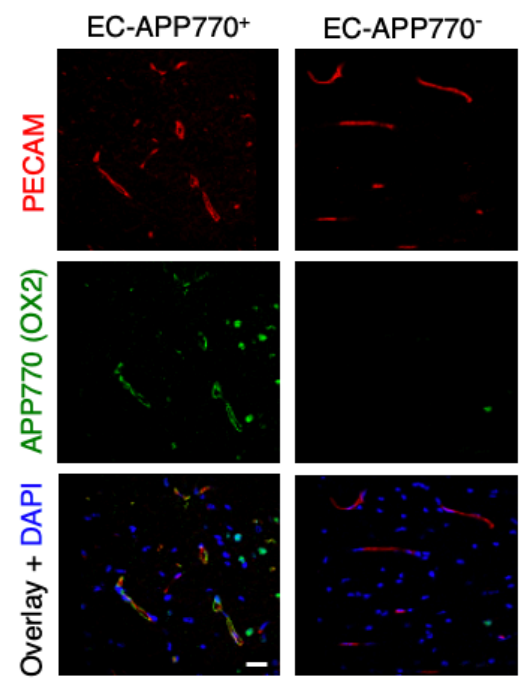

b
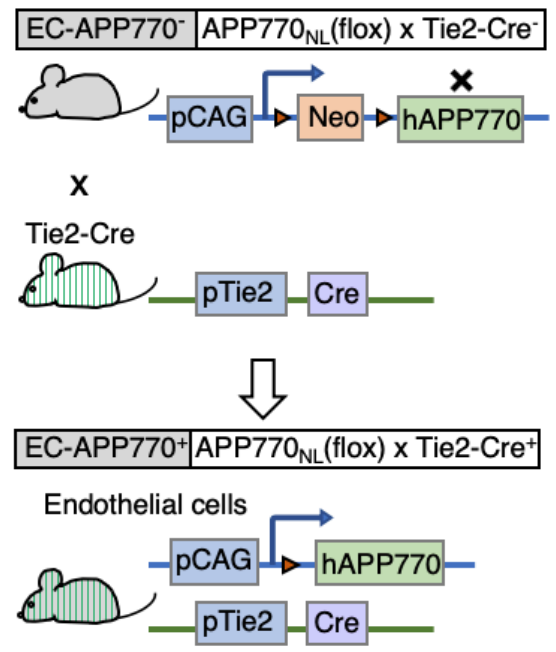

$\mathbf{e}$

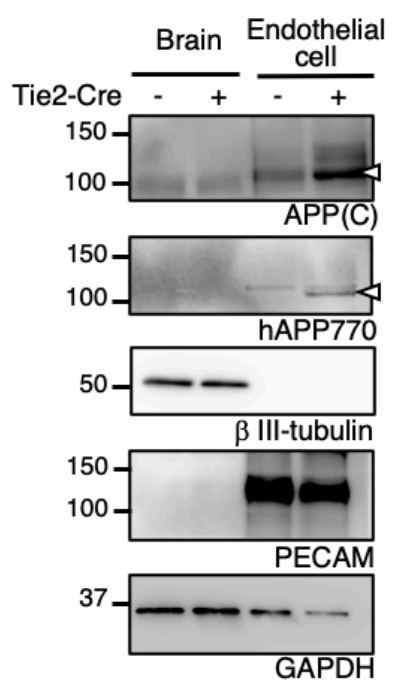

Figure 1. Endothelial APP expression mice.

(a) Biochemical measurement of blood sAPP levels in human, rat, and mouse samples. Plasma and serum levels of sAPP770 in humans $(n=8)$ and sAPP in rats $(n=3)$ and mice $(n=3)$ were respectively quantified by sandwich ELISA. Data show mean \pm s.e.m. (b) Schematic drawing showing endothelial-specific hAPP770 expression in mice. (c) Mouse genotype identified by PCR. In the top image, the $650 \mathrm{bp}$ band is derived from the APP770 floxed allele. The bottom image shows the Tie2-Cre transgene (230 bp band). (d) Endothelial human APP770 expression in EC-APP $770^{+}$mice. Immunohistochemical analyses of cortical sections of EC-APP $770^{+}$and EC-APP770 mice with anti-hAPP770 and anti-PECAM antibodies. Scale bar: $20 \mu \mathrm{m}$. (e) Biochemical examination of hAPP770 expression in endothelial cells. Lysates from the brains or isolated endothelial cells from EC-APP770 ${ }^{+}$and EC-APP770 mice were analyzed by western blotting for APP, hAPP770, $\beta$ III-tubulin, PECAM and GAPDH. 


\section{Fig 2}

a
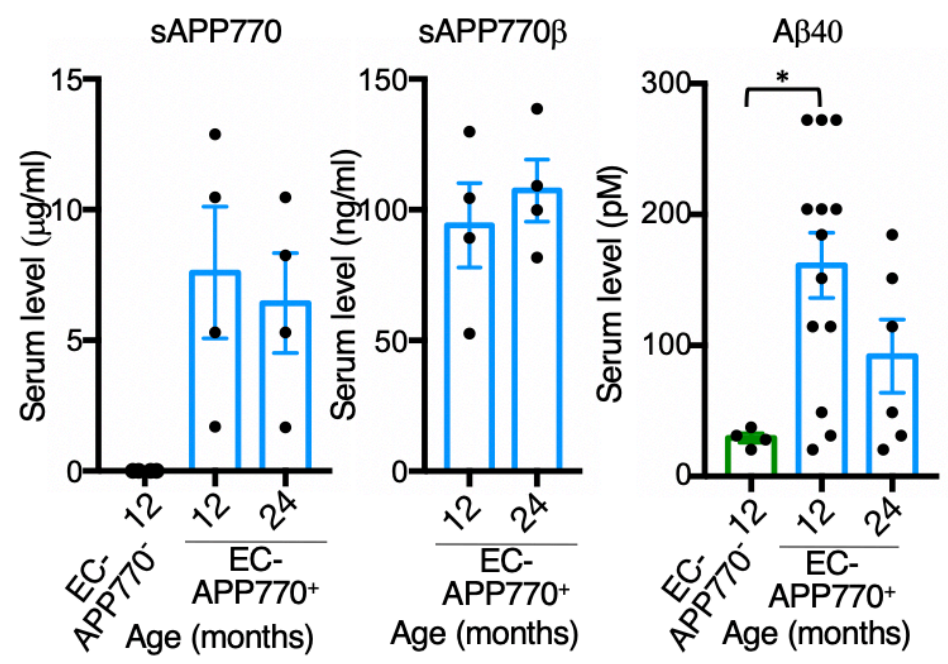

C

Cortex

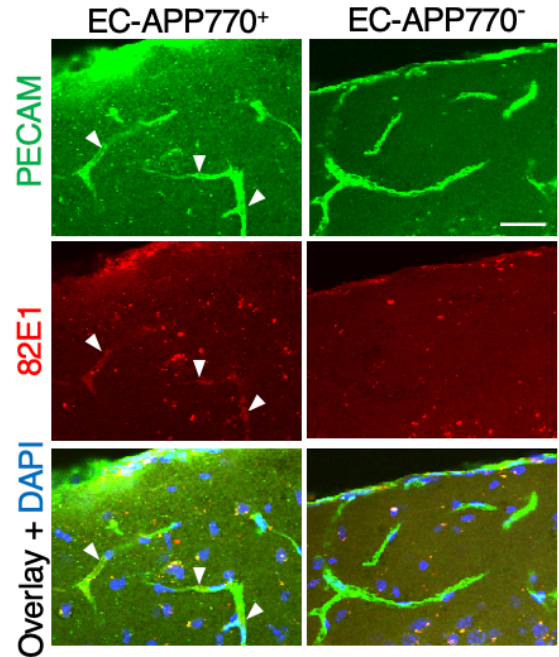

b
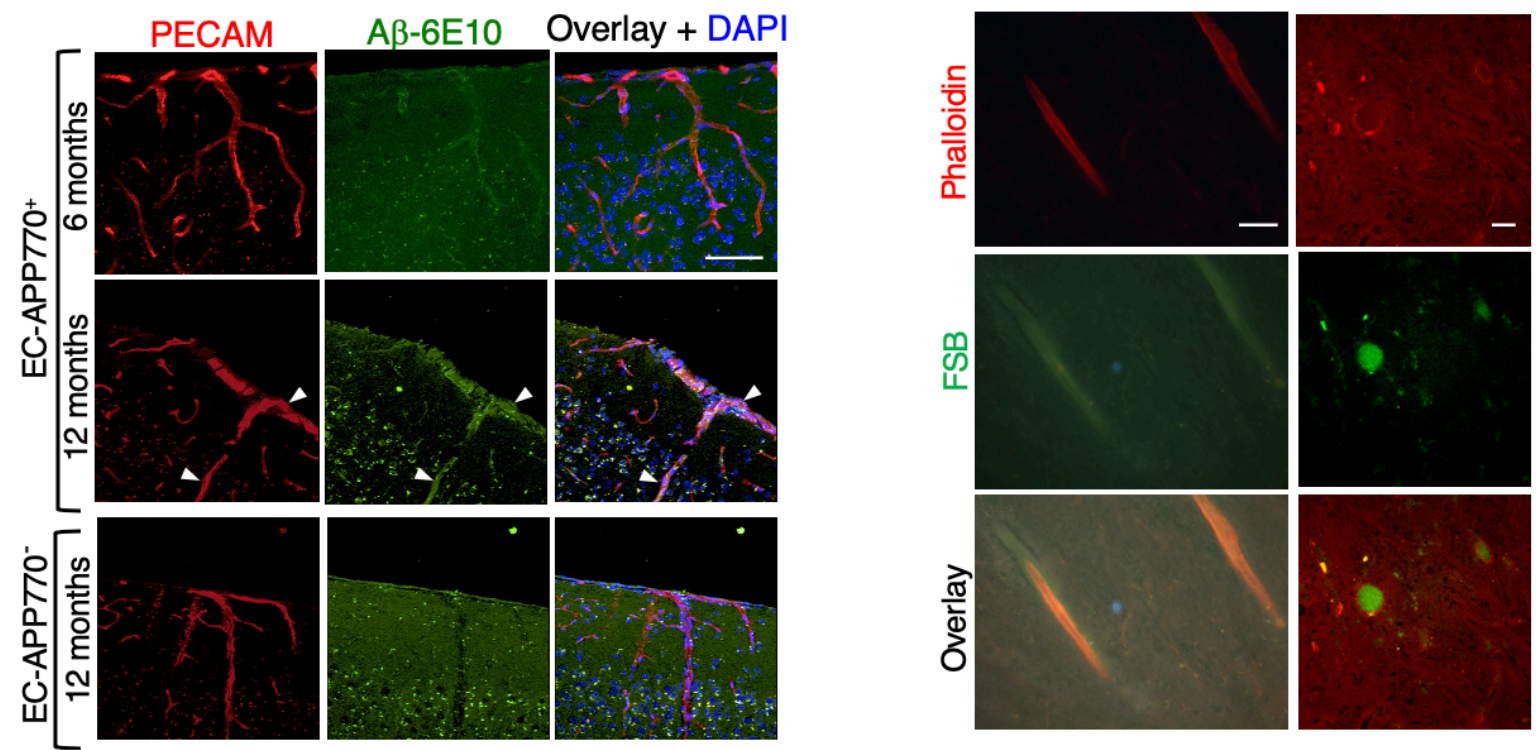

Figure 2. Aged EC-APP ${ }^{+}$mice show $\mathrm{A} \beta$ deposition in brain blood vessels.

(a) Serum levels of sAPP770, sAPP770 $\beta$ and A 340 in EC-APP770 ${ }^{+}$and EC-APP770- mice are shown as the mean \pm s.e.m. (n=4-13). (b) Immunohistochemical analysis of brain cortical sections from the EC-APP770 ${ }^{+}$( 6 and 12 months old) and EC-APP770- mice (12 months old) using antiPECAM and anti-A $\beta$ (6E10) antibodies. Arrowheads indicate 6E10-positive endothelial cells. Scale bar: $50 \mu \mathrm{m}$. (c) Brain cortex sections from 12-month-old EC-APP770 ${ }^{+}$and EC-APP770mice were stained by $82 \mathrm{E} 1$ for $\mathrm{A} \beta$ oligomers and anti-PECAM antibodies. Arrowheads indicate 82E1-positive endothelial cells. Scale bar: $20 \mu \mathrm{m}$. (d) Amyloid deposition in cortical blood vessels of 12-month-old EC-APP770 ${ }^{+}$mice was detected with FSB and Alexa546-phalloidin. Scale bar: $20 \mu \mathrm{m}$. 


\section{Fig 3}

a
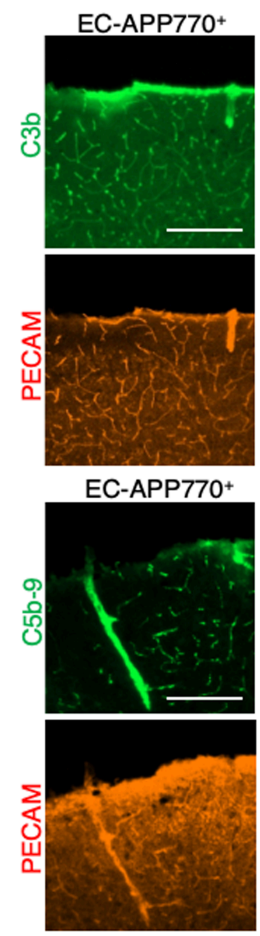

d
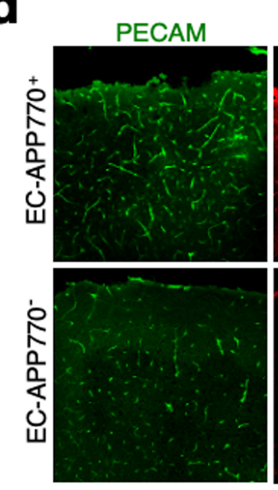

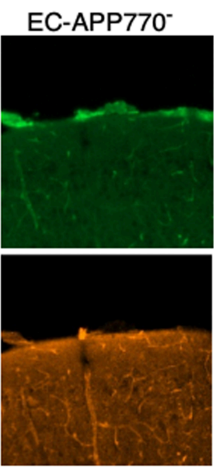

EC-APP770-

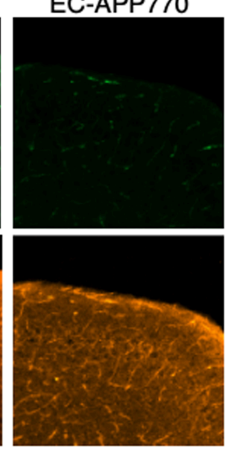

Fibrin

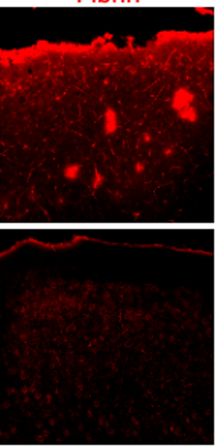

b

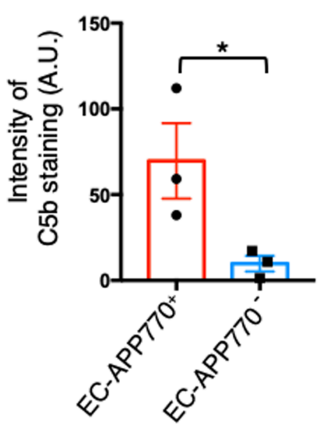

C

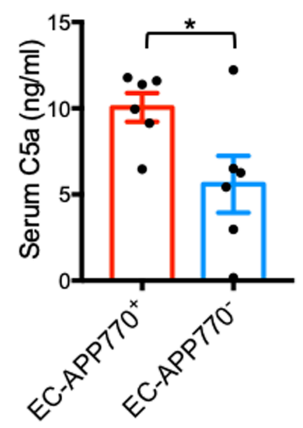

e
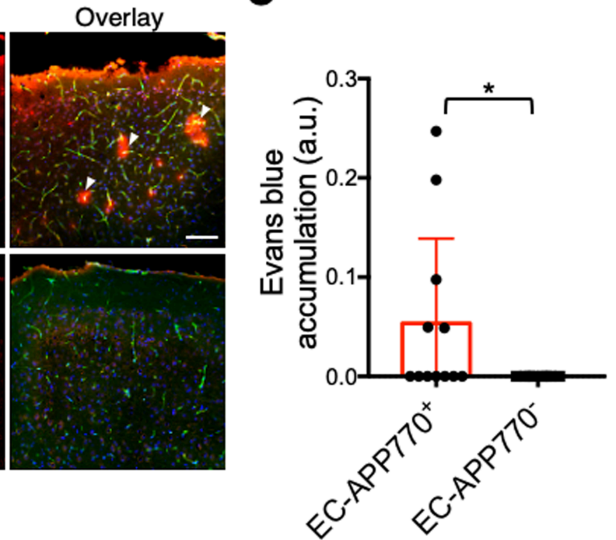

Figure 3. Deposition of activated complement components in brain blood vessels and presence of microhemorrhage are prominent features of aged EC-APP770 ${ }^{+}$mice.

(a)Brain cortical sections from 12-month-old EC-APP770 ${ }^{+}$and EC-APP770- mice were stained for C3b and C5b-9 complex with PECAM. Scale bar: $200 \mu \mathrm{m}$. (b) Signal intensities of C5b-9 were shown as the mean \pm s.e.m. $(n=3)$. Student's $t$-test, $\mathrm{p}<0.05$. (c) Serum C5b levels in 12month-old EC-APP770 ${ }^{+}$and EC-APP770 ${ }^{-}$mice, determine d by sandwich ELISA, are shown as the mean \pm s.e.m. $(n=6)$. Student's $t$-test, $\mathrm{p}<0.05$. (d) Brain cortical sections from 13-month-old EC-APP $770^{+}$and EC-APP770- mice were stained for fibrin and PECAM. Arrowheads indicate fibrin leakage. Scale bar: $200 \mu \mathrm{m}$. (e) Quantification of Evans blue intensity in brains from 13month-old EC-APP770 ${ }^{+}$and EC-APP770- mice are shown as the mean \pm s.e.m. $(\mathrm{n}=8)$. Student's $t$-test, $\mathrm{p}<0.05$. 


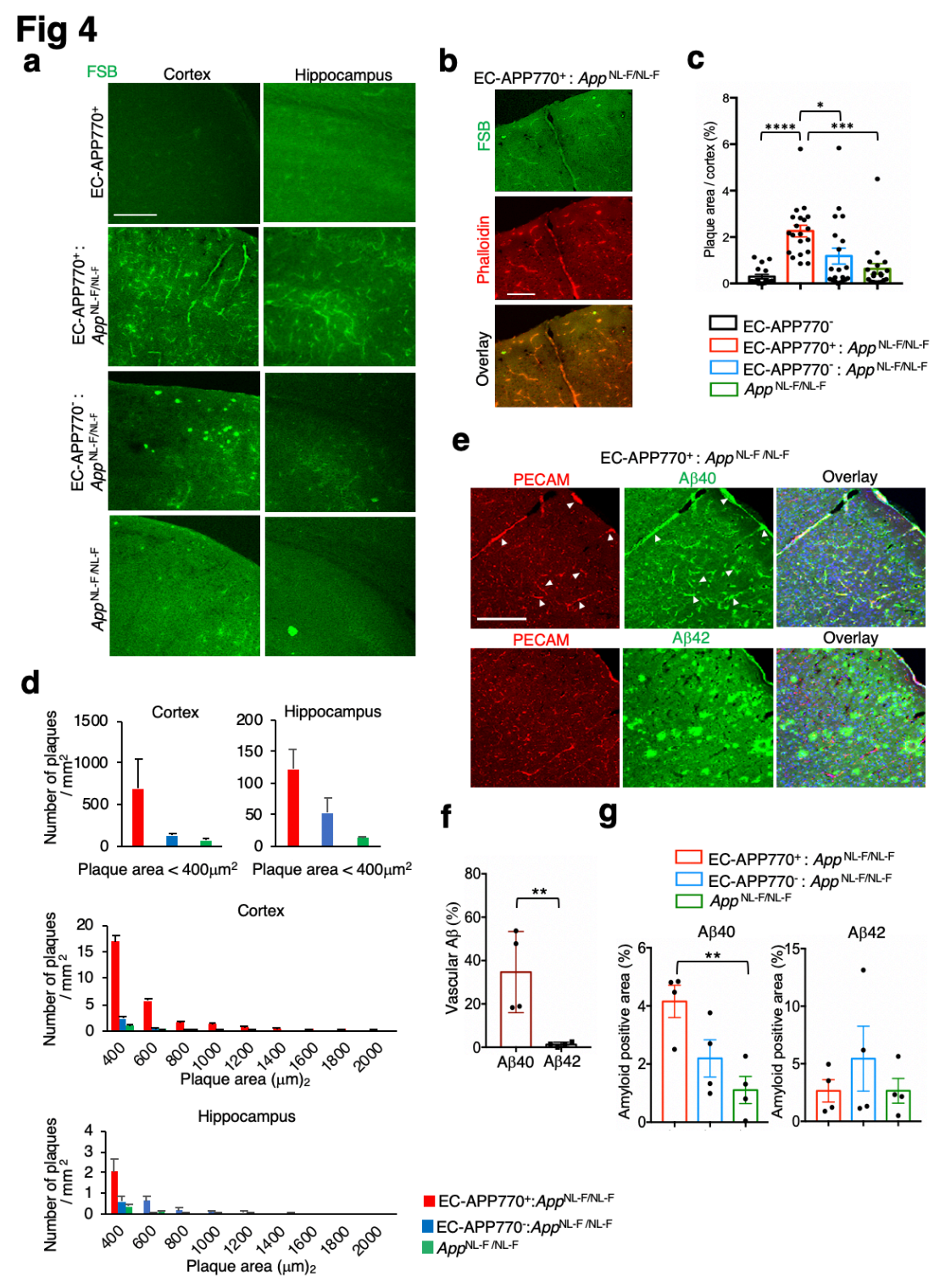

Figure 4. Offspring of EC-APP770 ${ }^{+}$mice crossed with APP-KI mice exhibit marked A $\beta$ deposition in brain blood vessels.

Cortical and hippocampal sections from 15 -month-old EC-APP770,$\quad$ (a) EC-APP770 $: A P P^{\mathrm{NL}-}$ FNNL-F, EC-APP770": $A P P^{\text {NL-F NL-F }}$ and $A P P^{\text {NL-FNL-F }}$ mice were stained with FSB. Scale bar: $200 \mu \mathrm{m}$.

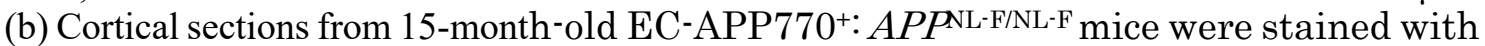
FSB and Alexa546-phalloidin. Scale bar: $100 \mu \mathrm{m}$. (c) Percentage of FSB-positive plaque area per brain cortex is shown as the mean \pm s.e.m. $(n=4)$. One-way ANOVA with Tukey's multiple comparison test, ${ }^{*}, \mathrm{p}<0.05{ }^{* *}, \mathrm{p}<0.001$. (d) FSB-positive amyloid plaques in cortical and hippocampal sections from 15-month-old EC-

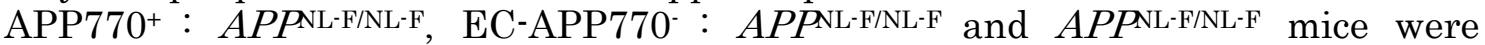
quantified and classified by size, and are shown in histogram form. (e) Brain cortical sections from 15-month-old EC-APP770 ${ }^{+}: A P P^{\mathrm{NL}-\mathrm{F} / \mathrm{NL}-\mathrm{F}}$ mice were stained for A $\beta 40$ and A $\beta 42$ with PECAM. Scale bar: $200 \mu \mathrm{m}$. (f) By the analysis of immunostained pictures of EC-APP770+: $A P P^{\mathrm{NL}-\mathrm{F} / \mathrm{NL}-\mathrm{F}}$ brain sections, percentage of PECAM-positive $\mathrm{A} \beta$ signals relative to total $\mathrm{A} \beta$ signals is shown as the mean \pm s.e.m. $(\mathrm{n}=4)$. Student's $t$ test, $\mathrm{p}<0.001$. (g) Percentage of amyloid positive area per brain cortex is shown as the mean \pm s.e.m. $(\mathrm{n}=4)$. One-way ANOVA with Tukey's multiple comparison test, **, $\mathrm{p}<0.001$. 
Supplementary Table 1. Antibodies used in this study

\begin{tabular}{|c|c|c|}
\hline Primary antibody & Secondary antibody & Application \\
\hline $\begin{array}{l}\text { Rabbit anti-APP770 } \\
\text { (IBL-Japan, \#18961, 1:50) }\end{array}$ & $\begin{array}{l}\text { Alexa 488-donkey anti-rabbit } \\
\text { (Thermo, A-11008, 1:300) }\end{array}$ & $\begin{array}{l}\text { Immunofluorescent detection in } \\
\text { Figure 1d }\end{array}$ \\
\hline $\begin{array}{l}\text { Rat anti-mPECAM } \\
\text { (Biolegend, MEC13.1, 1:50) }\end{array}$ & $\begin{array}{l}\text { Alexa488-donkey anti-rat } \\
\text { (Thermo, A-11006, 1:300) }\end{array}$ & $\begin{array}{l}\text { Immunofluorescent detection in } \\
\text { Figure } 2 c, 3 c\end{array}$ \\
\hline $\begin{array}{l}\text { Rabbit anti-APPC) } \\
\text { (IBL-Japan, \#18961, 1:100) }\end{array}$ & $\begin{array}{l}\text { HRP-conjugated anti-rabbit } \\
\text { (GE Healthcare, NA934, 1:3000) }\end{array}$ & $\begin{array}{l}\text { Western blot analysis in Figure } \\
\text { 1e }\end{array}$ \\
\hline $\begin{array}{l}\text { Rabbit anti-hAPP770 } \\
\text { (IBL-Japan, \#18961, 1:100) }\end{array}$ & $\begin{array}{l}\text { HRP-conjugated anti-rat IgG } \\
\text { (GE Healthcare, NA935, 1:3000) }\end{array}$ & $\begin{array}{l}\text { Western blot analysis in Figure } \\
\text { 1e }\end{array}$ \\
\hline $\begin{array}{l}\text { Rabbit anti-beta III tubulin } \\
\text { (Abcam, ab18207, 1:400) }\end{array}$ & $\begin{array}{l}\text { HRP-conjugated anti-rabbit } \\
\text { (GE Healthcare, NA934, 1:3000) }\end{array}$ & $\begin{array}{l}\text { Western blot analysis in Figure } \\
\text { 1e }\end{array}$ \\
\hline $\begin{array}{l}\text { Rat anti-mPECAM } \\
\text { (Biolegend, MEC13.1, 1:1000) }\end{array}$ & $\begin{array}{l}\text { HRP-conjugated anti-rat } \\
\text { (GE Healthcare, NA935, 1:3000) }\end{array}$ & $\begin{array}{l}\text { Western blot analysis in Figure } \\
\text { 1e }\end{array}$ \\
\hline $\begin{array}{l}\text { mouse anti-GAPDH } \\
\text { (Merck, mAB374, 1:1000) }\end{array}$ & $\begin{array}{l}\text { HRP-conjugated anti-mouse } \\
\text { (GE Healthcare, NA931, 1:3000) }\end{array}$ & $\begin{array}{l}\text { Western blot analysis in Figure } \\
\text { 1e }\end{array}$ \\
\hline $\begin{array}{l}\text { Rat anti-mPECAM } \\
\text { (Biolegend, MEC13.1, 1:50) }\end{array}$ & $\begin{array}{l}\text { Alexa546-donkey anti-rat } \\
\text { (Thermo, A-11030, 1:300) }\end{array}$ & $\begin{array}{l}\text { Immunofluorescent detection in } \\
\text { Figure } 1 \mathrm{~d}, 2 \mathrm{~b}, 3 \mathrm{a}, 4 \mathrm{e}\end{array}$ \\
\hline $\begin{array}{l}\text { Mouse anti-amyloid } \beta \\
\text { (Biolegend, 6E10, 1:100) }\end{array}$ & $\begin{array}{l}\text { Alexa488-donkey anti-mouse } \\
\text { (Thermo, A-11001, 1:300 ) }\end{array}$ & $\begin{array}{l}\text { Immunofluorescent detection in } \\
\text { Figure } 2 b\end{array}$ \\
\hline $\begin{array}{l}\text { Mouse anti-amyloid } \beta \\
\text { (IBL-Japan, 82E1, 1:50) }\end{array}$ & $\begin{array}{l}\text { Alexa546-donkey anti-mouse } \\
\text { (Thermo, A-11030, 1:300) }\end{array}$ & $\begin{array}{l}\text { Immunofluorescent detection in } \\
\text { Figure } 2 c\end{array}$ \\
\hline $\begin{array}{l}\text { Mouse anti-C3/C3b } \\
\text { (Abcam, ab11871, 1:50) }\end{array}$ & $\begin{array}{l}\text { Alexa488-donkey anti-mouse } \\
\text { (Thermo, A-11001, 1:100) }\end{array}$ & $\begin{array}{l}\text { Immunofluorescent detection in } \\
\text { Figure } 3 \mathrm{a}\end{array}$ \\
\hline $\begin{array}{l}\text { Mouse anti-C5b-9 } \\
\text { (Abcam, ab66768, 1:100) }\end{array}$ & $\begin{array}{l}\text { Alexa488-donkey anti-mouse } \\
\text { (Thermo, A-11001, 1:100) }\end{array}$ & $\begin{array}{l}\text { Immunofluorescent detection in } \\
\text { Figure } 3 \mathrm{a}\end{array}$ \\
\hline $\begin{array}{l}\text { Mouse anti-fibrin } \alpha \text {-chain IgM } \\
(\text { Abcam, ab19079, 1:50) }\end{array}$ & $\begin{array}{l}\text { Alexa546-anti mouse IgM } \\
\text { (Thermo A-21045, 1:100) }\end{array}$ & $\begin{array}{l}\text { Immunofluorescent detection in } \\
\text { Figure } 3 c\end{array}$ \\
\hline $\begin{array}{l}\text { Mouse anti-amyloid } \beta(1-40) \\
\text { (IBL-Japan, } \# 10047,1: 50)\end{array}$ & $\begin{array}{l}\text { Biotin-goat anti-mouse } \\
(\text { Thermo, 31800, 1:100) }\end{array}$ & $\begin{array}{l}\text { Immunofluorescent detection } \\
\text { using Tyramide Signal } \\
\text { Amplification (T20932) in } \\
\text { Figure 4e, S4 }\end{array}$ \\
\hline
\end{tabular}




\begin{tabular}{|c|c|c|}
\hline Rabbit anti-amyloid $\beta(1-42)$ & Biotin-goat anti-rabbit IgG & $\begin{array}{l}\text { Immunofluorescent detection } \\
\text { using Tyramide Signal } \\
\text { Amplification (T20932) in } \\
\text { Figure 4e, S4 }\end{array}$ \\
\hline $\begin{array}{l}\text { Mouse anti-aiolos } \\
\text { (Biolegend, clone 882, 1:1000) }\end{array}$ & $\begin{array}{l}\text { HRP-conjugated anti-mouse } \\
\text { (GE Healthcare, NA931, 1:3000) }\end{array}$ & $\begin{array}{l}\text { Western blot analysis in Figure } \\
\text { S3c }\end{array}$ \\
\hline $\begin{array}{l}\text { Mouse anti-actin } \\
\text { (Sigma, AC-40, 1:1000) }\end{array}$ & $\begin{array}{l}\text { HRP-conjugated anti-mouse } \\
\text { (GE Healthcare, NA931, 1:3000) }\end{array}$ & $\begin{array}{l}\text { Western blot analysis in Figure } \\
\text { S3c }\end{array}$ \\
\hline \multicolumn{2}{|l|}{$\begin{array}{l}\text { Alexa555-conjugated anti-hAPP } \\
(82 \mathrm{E} 1)\end{array}$} & $\begin{array}{l}\text { In vivo fluorescence imaging in } \\
\text { Figure } \mathrm{S} 1\end{array}$ \\
\hline
\end{tabular}




\section{Supplementary Fig 1}

\section{EC-APP770+}
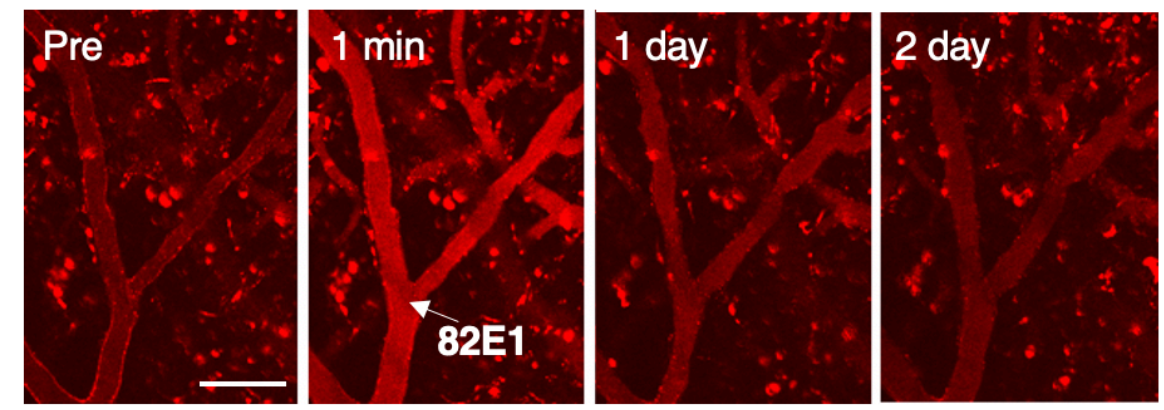

\section{EC-APP770-}
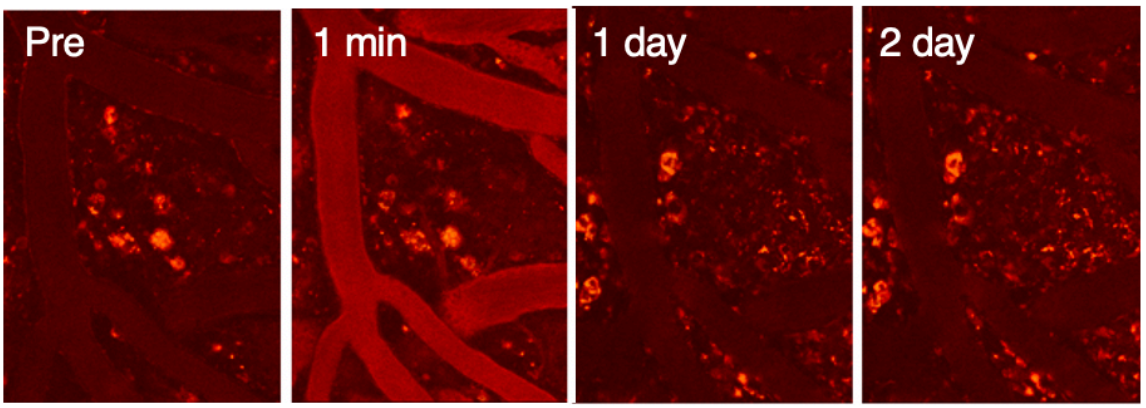

Supplementary Figure 1. Detection of A $\beta$ oligomer in EC-APP770 ${ }^{+}$mice.

To detect cerebrovascular $A \beta$, in vivo fluorescence imaging was performed prior to (Pre) and at 1 minute (1 min), and 1 day (D1) and 2 days (D2) after intravenous injection of labeled 82E1 antibody using 22-month-old EC-APP770 (upper panels) and EC-APP770- (lower panels) mice. Scale bar: $100 \mu \mathrm{m}$. 


\section{Supplementary Fig 2}
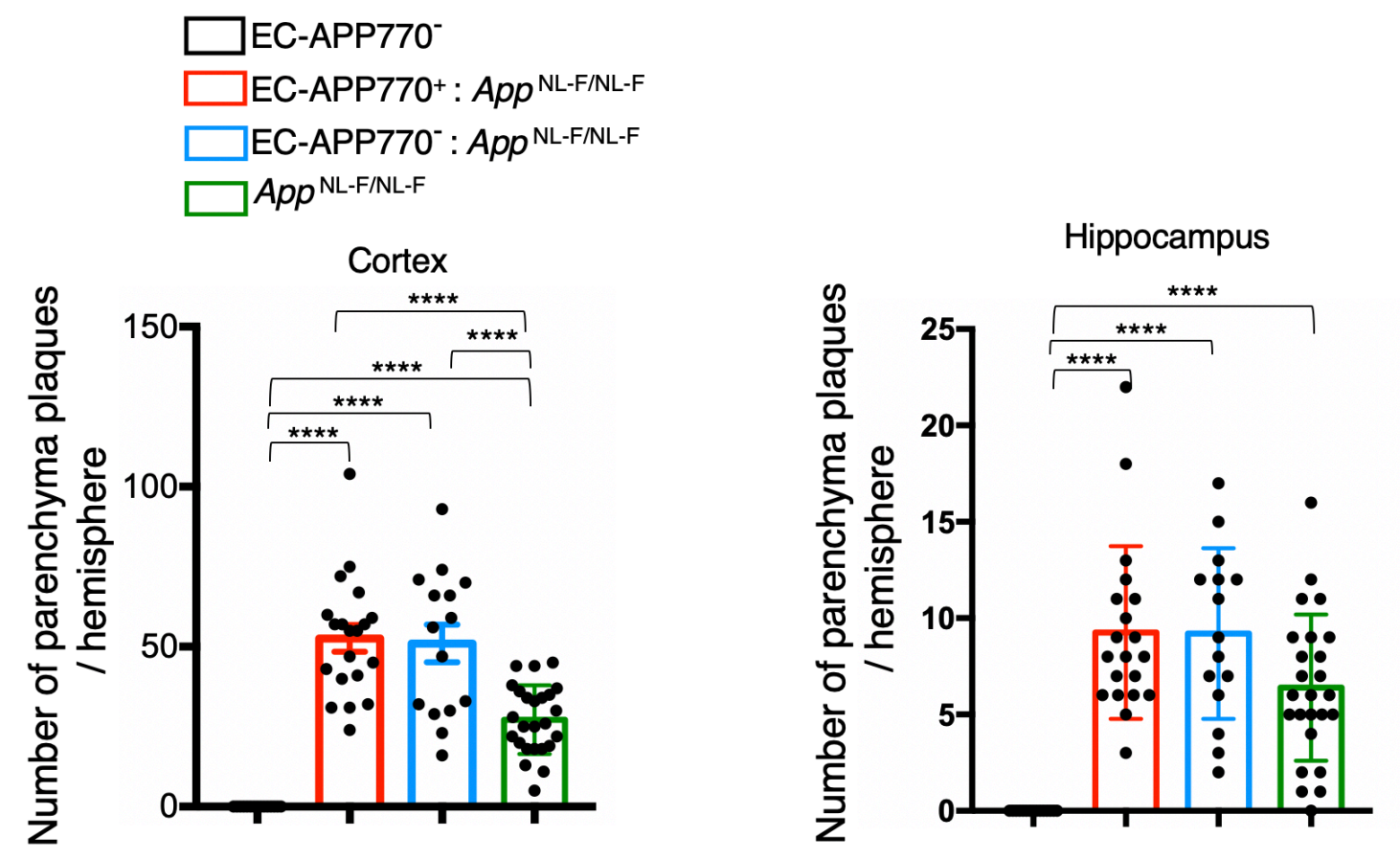

Supplementary Figure 2. Similar parenchymal amyloid plaque deposition between $A P P^{\mathrm{NL}-}$

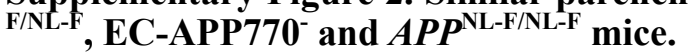

The number of FSB-positive amyloid plaques in brain parenchyma of 15-month-old ECAPP770 ${ }^{+}$, EC-APP $770^{+}: A P P^{\mathrm{NL}-F / N L-F}$, EC-APP770 $: A P P^{\mathrm{NL}-\mathrm{F} / \mathrm{NL}-\mathrm{F}}$ and $A P P^{\mathrm{NL}-\mathrm{F} / \mathrm{NL}-\mathrm{F}}$ mouse brain sections were quantified and shown as the mean \pm s.e.m. $(\mathrm{n}=4$ mice; 5 sections were counted per mouse). 


\title{
Supplementary Fig 3
}

a

\author{
Ikzf3 gene (zinc finger protein Aiolos)
}

Chr 11: 98,464,610

F2 R2 R3

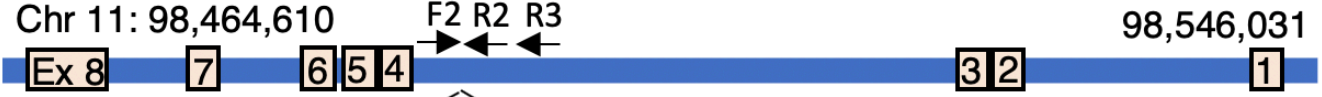
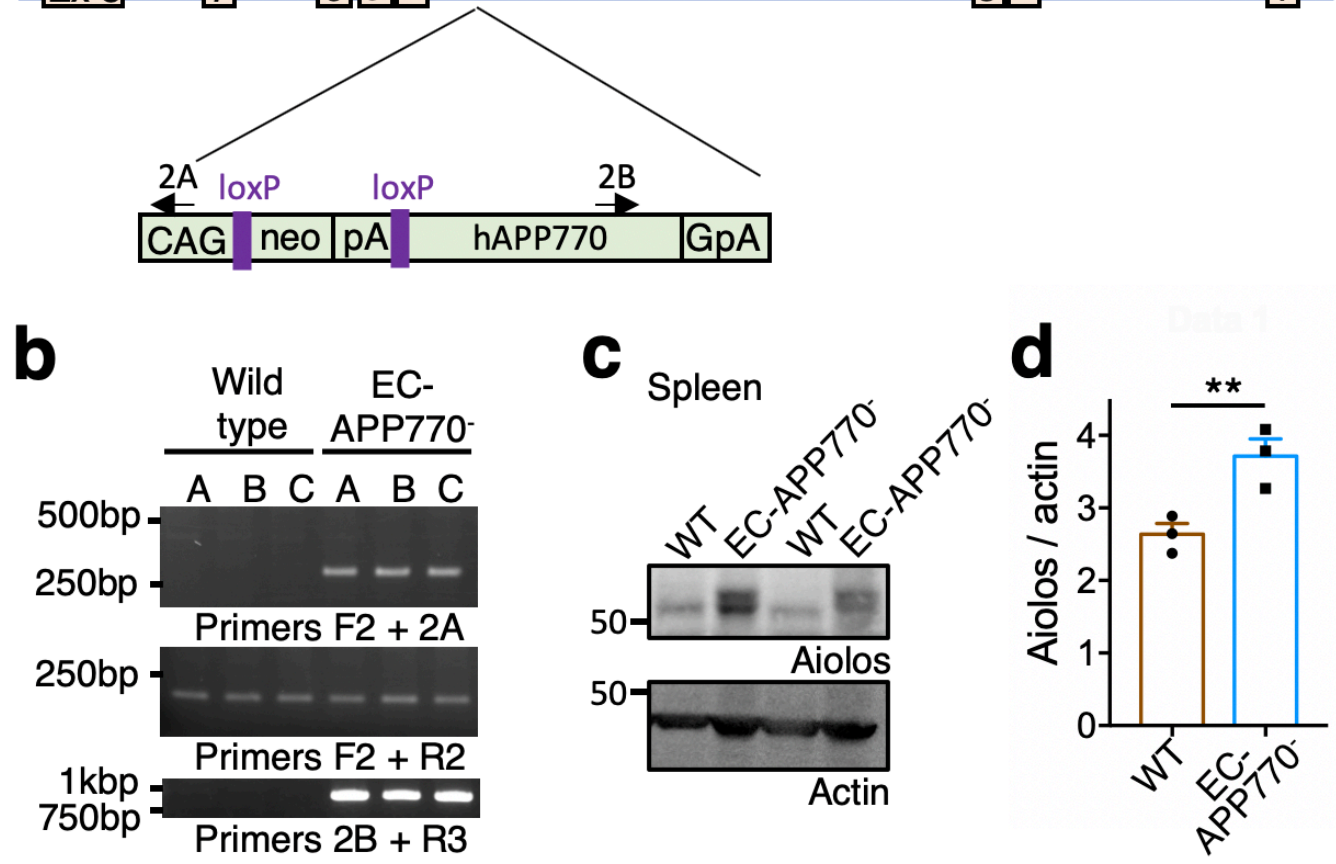

Supplementary Figure 3. Identification of integration locus of hAPP770 transgene.

(a) Schematic diagram showing hAPP770 transgene located in the Ikzf3 locus on chromosome 11. Positions of primers to validate the insertion site are also shown. (b) Insertion site was verified by PCR for left junction, inserted genome region, and right junction. (c) Spleen lysates from wild type (WT) and EC-APP ${ }^{-}$mice were analyzed by western blot for Aiolos and actin. (d) The level of Aiolos in the spleens from both types of mice are shown as the mean \pm s.e.m. $(n=3)$. Student's $t$-test, $\mathrm{p}<0.01$. 


\section{Supplementary Fig 4}
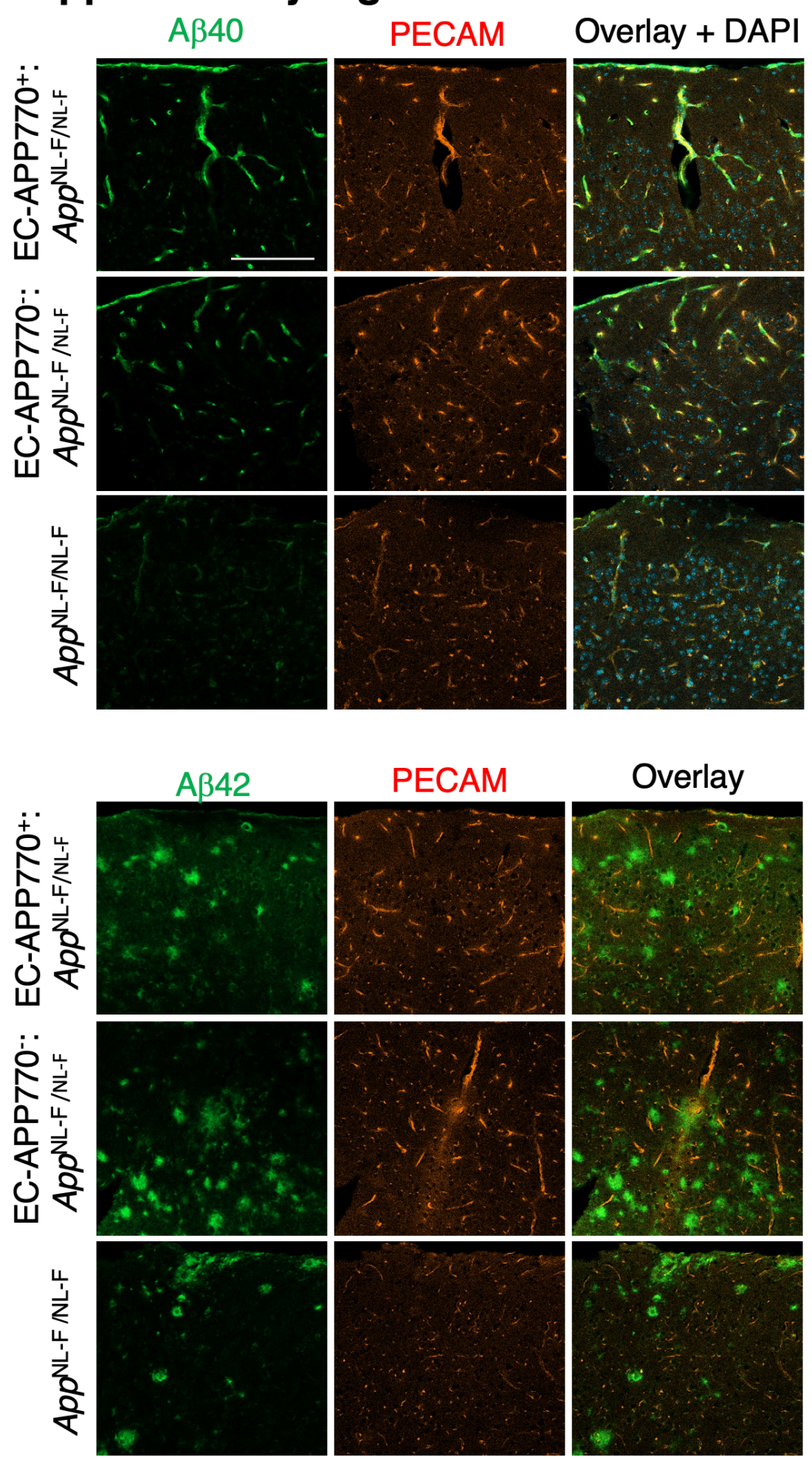

Supplementary Figure 4. $A \beta 40$ and $A \beta 42$ are accumulated differently in the brains of EC-

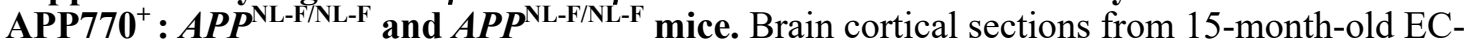
$\mathrm{APP} 770^{+}: A P P^{\mathrm{NL}-F / N L-F}, \mathrm{EC}-\mathrm{APP} 770^{-}: A P P^{\mathrm{NL}-\mathrm{F} / \mathrm{NL}-\mathrm{F}}$ and $A P P^{\mathrm{NL}-\mathrm{F} / \mathrm{NL}-\mathrm{F}}$ mice were stained for $\mathrm{A} \beta 40$ and A $\beta 42$ with PECAM. Scale bar: $100 \mu \mathrm{m}$. 


\section{Appendix Fig. 1d}

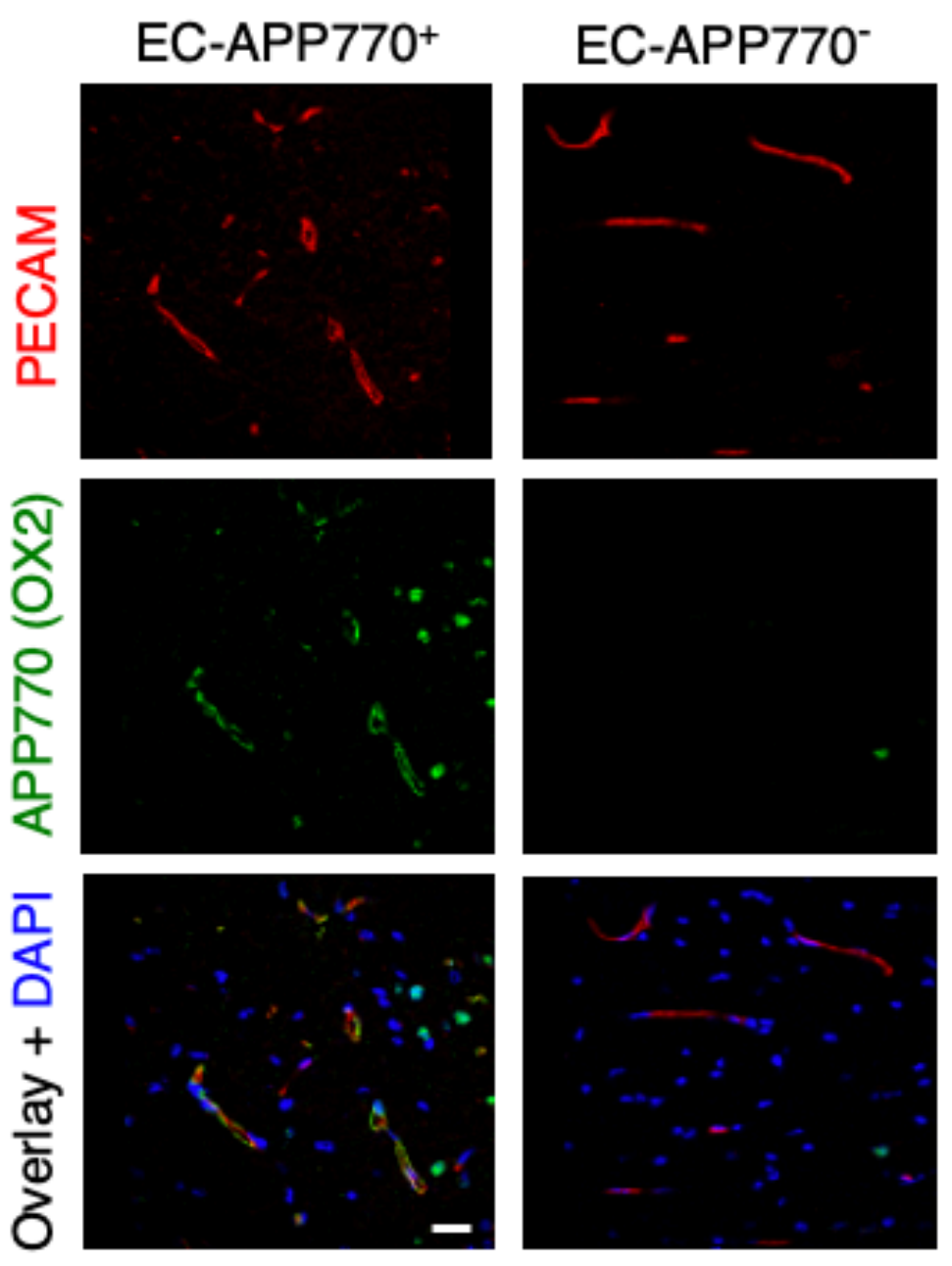




\section{Appendix Fig. 3d}

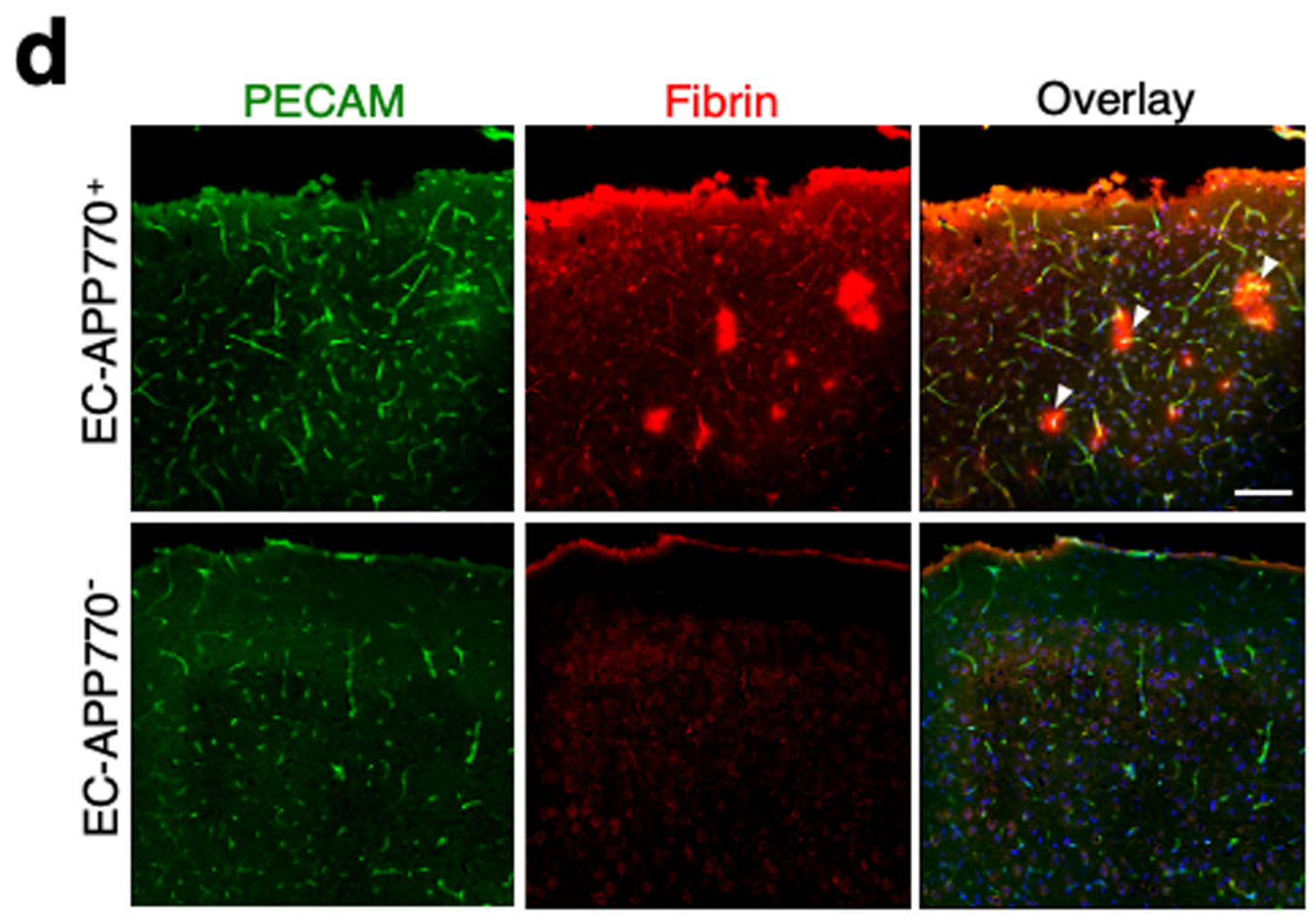


Appendix Fig. 4a

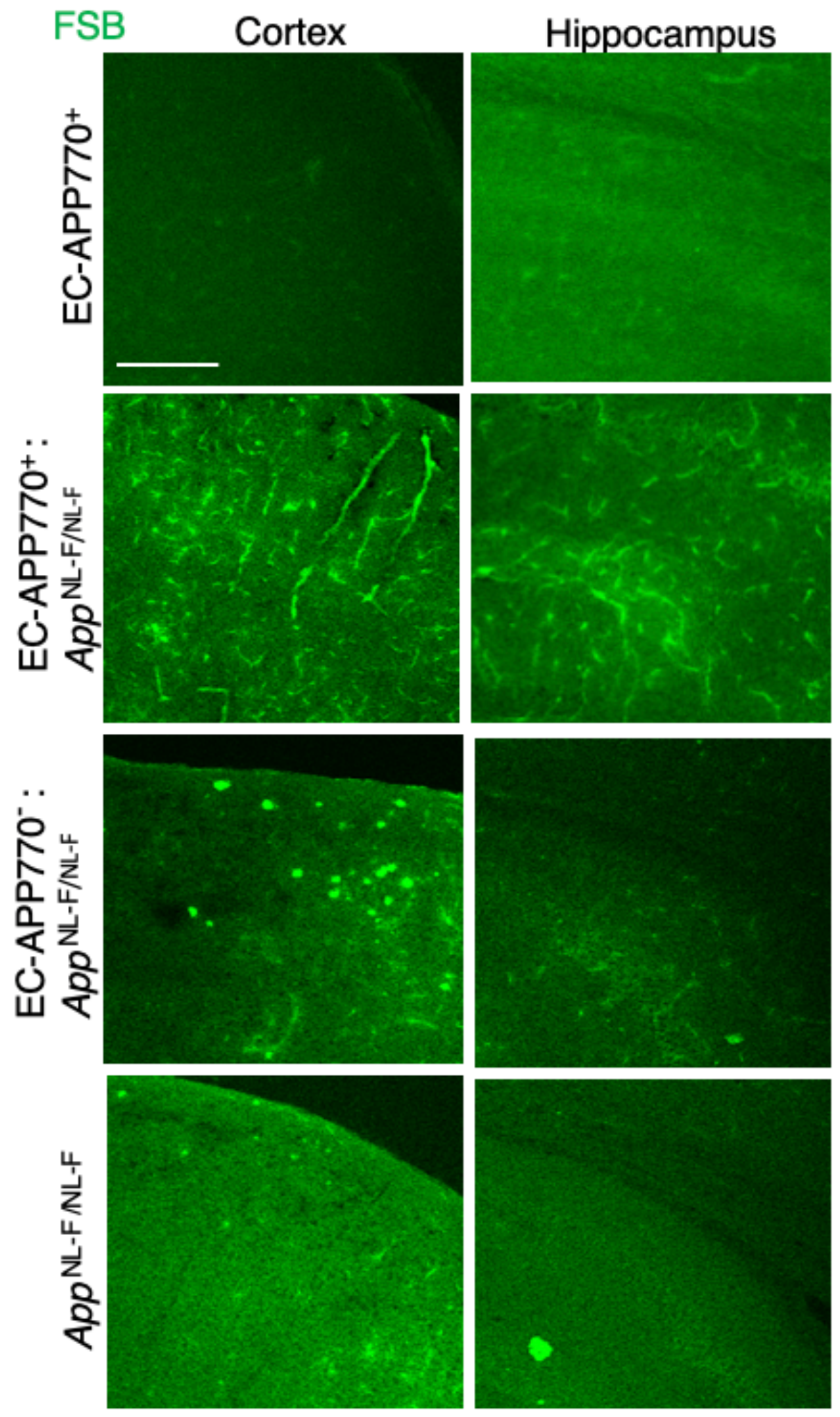




\section{Appendix Fig 4b, e}

b
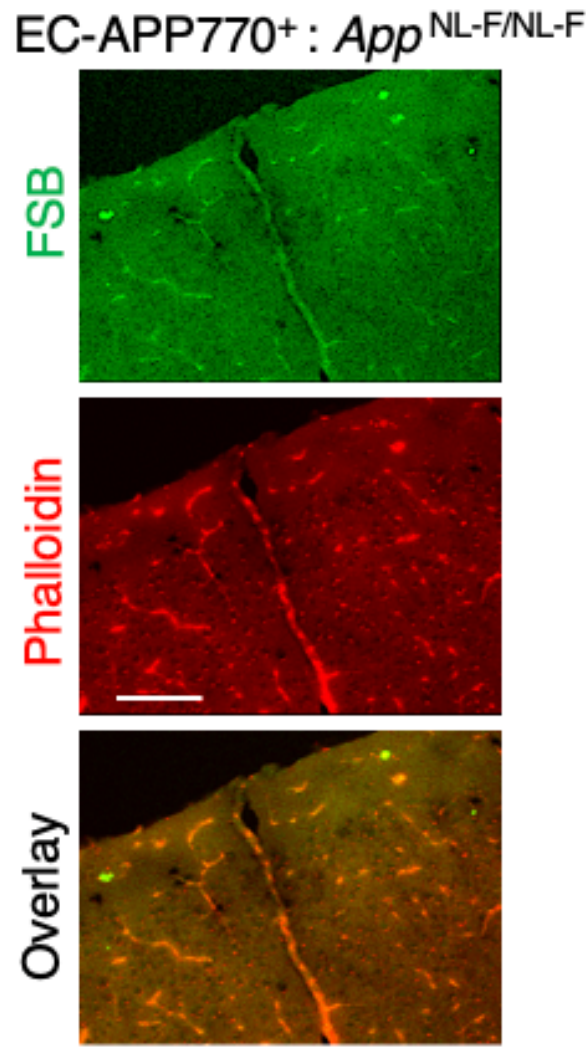

e

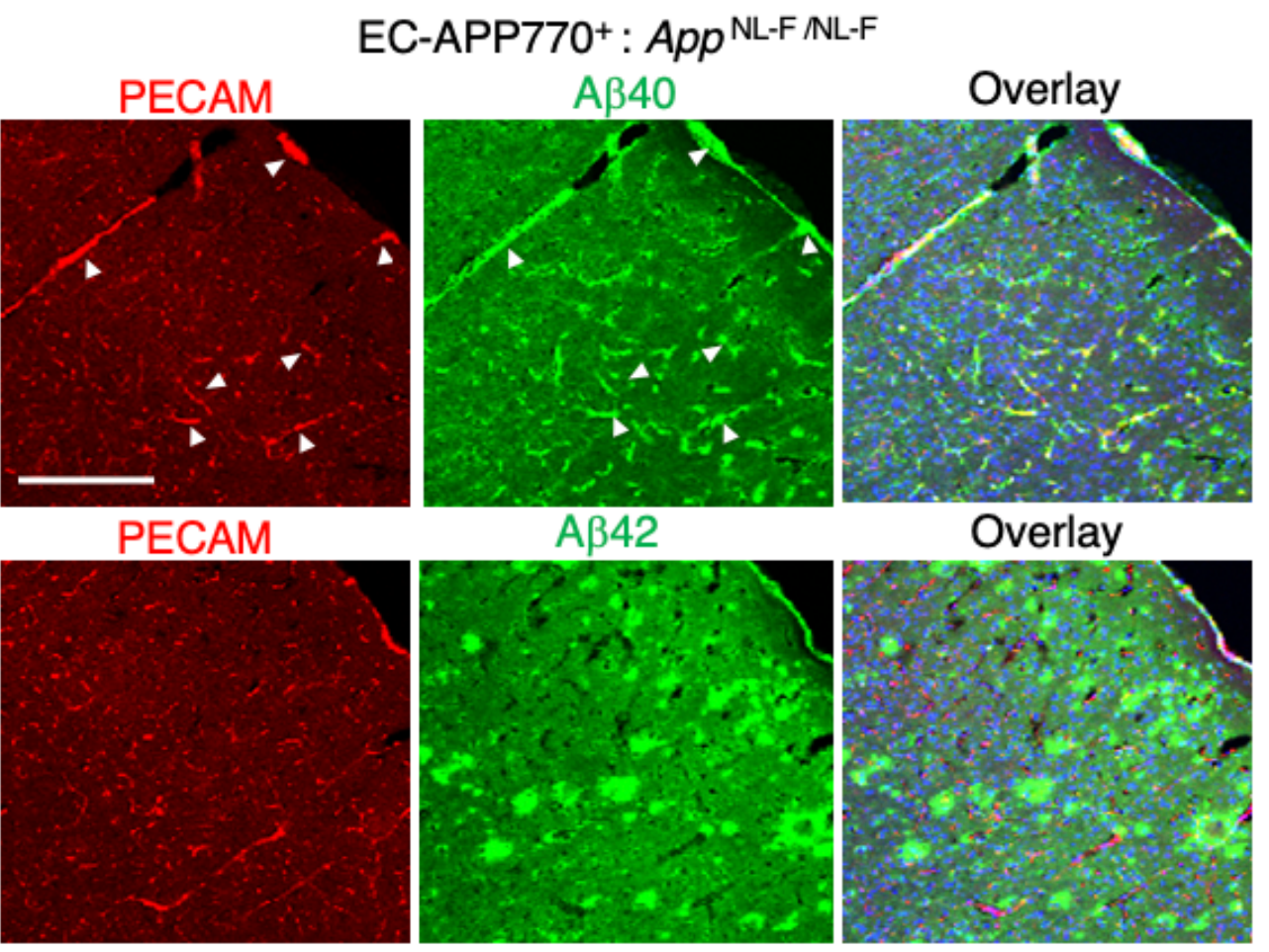

